\title{
Mechanistic Considerations of the Protonation and Fragmentation of Highly Functionalized Molecules in Fast Atom Bombardment: High Resolution Mass Spectrometry and Tandem Mass Spectrometry Analysis of the Ions Formed by Fast Atom Bombardment of Digoxin and Related Cardiac Glycosides
}

\author{
Karen J. Light and John Allison \\ Department of Chemistry, Michigan State University, East Lansing, Michigan, LSA
}

\begin{abstract}
High resolution mass spectrometry and tandem mass spectrometry analyses of the major ions of digoxin formed by fast atom bombardment are presented and discussed to investigate the mechanisms through which fragment ions are formed. Similar cardiac glycosides are also analyzed to provide support for the proposed fragment assignments. Remote site fragmentation with the charge localized on the aglycone portion of the molecule may provide an explanation for the fragment ions observed in these studies because the majority of these ions contain the aglycone portion of the molecule. The results obtained parallel previously reported results from an ammonia chemical ionization mass spectral study of cardiac glycosides. (/ Am Soc Mass Spectrom 1990, 1, 455-472)
\end{abstract}

$\mathrm{T}$ III cornerstone of mass spectrometry, on which its power for structure elucidation is built, is the understanding of the mechanisms by which molecular ions fragment in the gas phase. For the ionization technique used most often in mass spectrometry, electron ionization (EI), fragmentation mechanisms have been well characterized and utilized to understand the relationship between the $m / z$ values and relative abundances of the ions formed and the structure of the compound under study [1]. When EI is utilized, the relative abundance of a fragment ion in a mass spectrum, as well as its $m / z$ value, gives some information on the structure of the ion, the environment in the molecule from which it is formed, and the type of mechanism involved in its formation [1]. However, mass spectrometry has moved away from EI-based techniques toward a variety of desorpfinn ionization techniques that can be applied to the analysis of larger, more highly functionalized molecules. While the number of ionization methods available for mass spectrometry is now substantial, the mechanisms through which fragment ions are formed via these methods are not well understood,

Address reprint requests to John Allison, Department of Chemistry, Michigan State University, East Lansing, MI 48824. and their establishment has nol been extensively pursued to date. Frequently there is little discussion of fragmentation mechanisms in the mass spectrometry analysis of large molecules, and those mechanisms that are proposed and utilized usually have not been substantiated. Often the interpretation relies only on the presence/absence of ion current at a particular $m / z$ value, with abundance information being of relatively little utility.

The understanding of fragmentation mechanisms not only facilitates the interpretation of mass spectra of unknown compounds, but is vital when known compounds are under study in which an isotopic label has been incorporated, and the position and extent of the label incorporation must be ascertained. This has become important for larger molecules in the study of metabolic pathways [2] in which a labeled compound is introduced into a system and its fate is followed with mass spectrometry, by monitoring label incorporation into metabolites. Thus, mechanistic aspects of fragmentation for larger molecules should be considered when ionization methods other than EI are used. As it is somewhat impractical to expect that extensive labeling studies be performed on large molecules, we evaluate here the use of the tools that are available on a conventional double-focusing sector instrumenthigh resolution mass spectrometry (peak matching) 
and collisionally activated dissociation (CAD) methodology-for providing insights into the ions produced by fast atom bombardment (FAB). In particular, we focus on the FAB mass spectra of cardiac glycosides, and further focus on the molecule digoxin. We have chosen a case where the protonated molecule and many fragment ions are observed in the FAB mass spectrum. The CAD spectra obtained from linked scanning at constant $B / E$ for the ions observed, and the results of accurate mass measurements, will be presented and discussed. We will assume that for this type of analyte molecule the dominant mode of ionization is essentially glycerol chemical ionization in which protonated glycerol (or some fragment ion derived from glycerol) protonates the desorbed neutral molecule in the gas phase, and fragmentation follows protonation [3].

The data will be evaluated in the context of basic questions concerning the site of protonation and fragmentation mechanisms for these highly functionalized molecules, typical of those studied by FAB and liquid secondary ion mass spectrometry (LSIMS).

\section{Experimental}

The cardiac glycosides were obtained from Sigma Chemical Co., St. Louis, MO, and were used without further purification. Acetyldigitoxin was purchased from ICN K\&K Laboratories, Cleveland, $\mathrm{OH}$. The samples were dissolved in methanol to concentrations of approximately $1 \mu \mathrm{g} \mu \mathrm{L}^{-1}$. Two microliters were transferred to the FAB probe tip and mixed with the glycerol matrix. All FAB analyses were performed on a JEOL HX-110 double-focusing mass spectrometer (JEOL, Ltd., Tokyo, Japan) of forward geometry with an accelerating voltage of $10 \mathrm{kV}$ and a FAB gun voltage of $6 \mathrm{kV}$ with xenon FAB gas. Peak matching was performed with a resolving power of 7,000 or more, using glycerol cluster ions as reference ions.

All CAD experiments were performed by linked scanning (at constant B/E) controlled with the JEOL JMA-DA5000 software and using helium as the collision gas. The ability to compare CAD spectra in terms of the daughter ions observed was important for their utility in the mechanistic considerations addressed in this article. This suggested the need for performing these $\mathrm{CAD}$ experiments under single collision conditions, as opposed to multiple collision conditions where $\mathrm{CAD}$ of $\mathrm{CAD}$ products could be observed. Therefore all $C A D$ experiments were performed by introducing helium into the collision cell so that the signal for the parent ion was attenuated by $10 \%$, which produced single collision conditions [4]. In our initial studies we were intrigued that low mass ions at $m / z 113$ and $m / z 131$ were dominant ions in the FAB spectrum of digoxin, but were not observed as CAD daughter ions of the $[\mathrm{M}] \mathrm{H}^{+}$ion of digoxin. This was particularly distressing in light of a previously re- ported CAD mass spectrum of digoxin in which these two low mass ions were observed [5]. Our preliminary $\mathrm{CAD}$ data were collected with no instrumental changes from that used in the FAB mode and with a tuning file that contained ions from $m / z 39$ to $m / z 984$ (from a mixture of KI and CsI). However, the B/E linked scanning software program used with the JEOL HX-110 double-focusing mass spectrometer to perform these $\mathrm{CAD}$ experiments requires a good magnetic field calibration table. A relation between the calibration table lowest mass number $\left(\mathrm{m}^{*}\right)$, the linked scan parent ion mass number $\left(m_{1}\right)$, and the lowest observable daughter ion $\left(\mathrm{m}_{2}\right)$ is suggested in the JEOL instruction manual by the following formula [6]: $\mathrm{m}^{*}=\left(\mathrm{m}_{2}\right)^{2} /\left(\mathrm{m}_{1}\right)$. Therefore a different calibration compound, Ultramark 1621, from PCR Inc., Gainesville, FL, was selected to allow for the construction of a tuning file that contained many low mass ions, with $m / z 1$ being the lowest mass ion included. In addition to this change of calibration compound, performing CAD experiments on the JEOL HX-110 requires repositioning the conversion dynode and opening the slit between the electric sector and the magnetic sector to enhance detection of low mass fragment ions that have lower kinetic energies than their parent ions [7]. These modifications allowed us to observe the expected low mass daughter ions at $m / z 113$ and $m / z 131$ from the protonated digoxin molecule.

In some cases, where the parent ion was within approximately $5 \mathrm{u}$ of a mass spectral peak derived from glycerol alone, interference from the glycerol matrix appeared in the $\mathrm{CAD}$ spectra and made it necessary to use an alternative matrix, thioglycerol. Another form of glycerol interference occurred when the parent ion selected for $\mathrm{CAD}$ analysis had a low relative abundance compared to the glycerol adduct ions. In this case, a cluster of ions $90,92,94$, and $96 u$ lower than the nominal mass of the parent ion, with successive losses of $90,92,94$, and $96 u$, appeared in the linked scan spectrum. These " 92 " losses were not observed when the matrix was thioglycerol, but were observed with glycerol alone. Therefore, it was determined that these ions originated from the glycerol matrix. The artifact peaks clustered $92 \mathrm{u}$ below the parent ion are denoted by $T$ in the $B / E$ mass spectra that are presented.

\section{Results}

The fast atom bombardment mass spectrum of digoxin - exact mass measurements and fragment ion assignments: The fragmentation pathways operative in the $\mathrm{FAB}$ analysis of digoxin are the subject of this article and thus discussion will begin by presenting the data obtained for digoxin. Initial assignments for the fragment ions are proposed to provide a basis for discussing the possible mechanism(s) of fragmentation. This creates a difficult situation because the identities of the frag- 

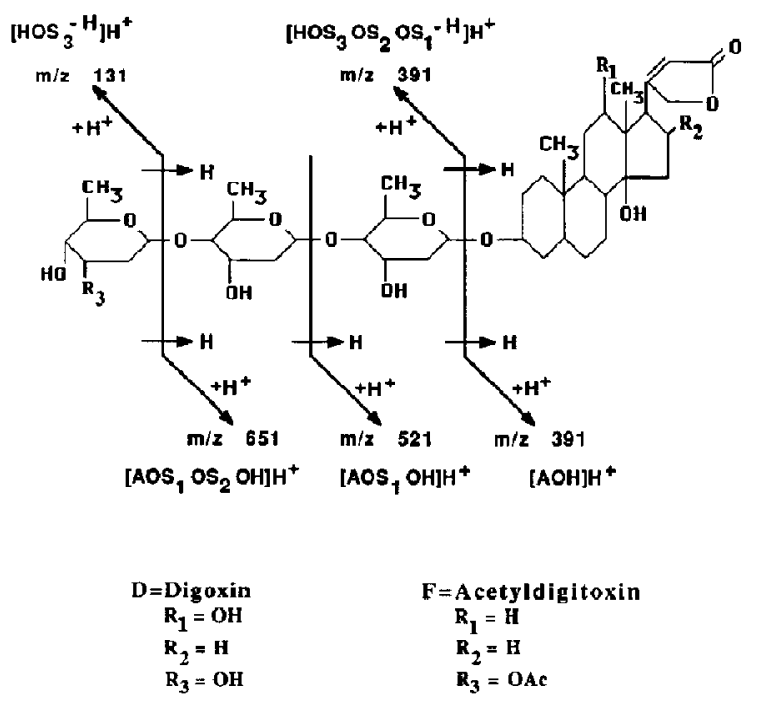

$\mathbf{F}=$ Acetyldigitoxin
$\mathbf{R}_{1}=H$
$\mathbf{R}_{2}=\mathrm{H}$
$\mathbf{R}_{3}=\mathrm{OAC}$

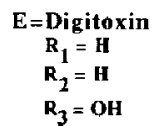

$$
\begin{gathered}
\mathbf{G}=\text { Gitoxin } \\
\mathbf{R}_{1}=\mathbf{H} \\
\mathbf{R}_{2}=\mathbf{O H} \\
\mathbf{R}_{3}=\mathbf{O H}
\end{gathered}
$$

Figure 1. Structures of the cardiac glycosides. The $m / z$ values of the fragment ions labeled on the figure are for digoxin.

ments are necessary for determining the fragmentation mechanism(s) and likewise the fragmentation mechanism is required to know the exact structure of the fragments that we wish to describe in the ionic assignments. Whereas mechanistic possibilities are being evaluated throughout this article, the nomenclature used to identify different fragments is the Light/Kassel/Allison scheme, which has previously been described [8]. The Light/Kassel/Allison scheme is designed as a precise shorthand for discussing both ionic and neutral variants of the types of molecules addressed in this article. This nomenclature allows for more mechanistic detail than the more common Domon/Costello nomenclature [9], which is mechanistically neutral. Where appropriate, reference is made to the Domon/Costello scheme to provide additional clarity for those readers more familiar with this latter system.

The structure of digoxin is shown in Figure 1 (case D). Also shown in Figure 1 are the proposed fragment ions for digoxin. The FAB mass spectrum of digoxin is shown in Figure $2 a$, and the linked scan spectrum of the $[\mathrm{M}] \mathrm{H}^{+}$ion of digoxin (where $\mathrm{M}$ is the intact molecule), $m / z 781$, is shown in Figure $2 b$. The FAB mass spectrum contains peaks representative of the

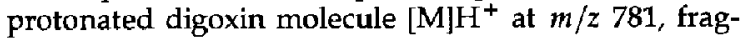
ment ions derived from the analyte digoxin, and the glycerol matrix adduct ions, [(glycerol) $n] \mathrm{H}^{+}$(denoted by *). All of the fragment ions appear at odd $\mathrm{m} / \mathrm{z}$ values and are thus even electron ions. There are a few types of ions that suggest patterns of fragmentation. The first of these is represented by the ion current at $m / z$ 651. The terminal glycosidic bond is cleaved such that the glycosidic oxygen remains on the fragment containing the aglycone. Although the actual fragmentation follows protonation, to demonstrate how the nomenclature scheme is used, consider the neutral digoxin molecule, designated as [ $\mathrm{AOS}_{1} \mathrm{OS}_{2} \mathrm{OS} \mathrm{OH}$ ]. If the $\mathrm{C}-\mathrm{O}$ bond of the terminal glycosidic linkage were cleaved as shown in Figure 1, two radical fragments would be formed with masses of 131 and $649 \mathrm{u}$. This bond cleavage appears to be accompanied by an $\mathrm{H}$-shift toward the glycosidic oxygen, producing two neutral species with masses of 130 and $650 \mathrm{u}$ that are designated by the Light/Kassel/Allison shorthand notation as $\left[\mathrm{HOS}_{3}^{-} \mathrm{H}\right]$ and $\left[\mathrm{AOS}_{1} \mathrm{OS}_{2} \mathrm{OH}\right]$, respectively. Both of these neutral species are observed in protonated form in the $\mathrm{FAB}$ mass spectrum at $m / z$ values of 131 and 651 , respectively (see Figure $2 \mathrm{a}$ ). These ions are labeled as $\left[\mathrm{HOS}_{3}^{-\mathrm{H}}\right] \mathrm{H}^{+}$and $\left[\mathrm{AOS}_{1} \mathrm{OS}_{2} \mathrm{OH}\right] \mathrm{H}^{+}$and are confurmed by exact mass measurements as shown in Table 1. In the designation scheme of Domon and Costello [9], these ions correspond to the $B_{1}$ and $Y_{2}$ fragments, respectively.

The tentative structural assignments of the fragment ions observed in the FAB mass spectrum of digoxin using the Light/Kassel/Allison scheme are presented in Table 1 , in addition to the designations based on the Domon/Costello nomenclature. Peak matching results, and the relative errors between the proposed structure exact mass calculations and the experimentally determined exact mass, are also given in Table 1. All uncertainties are within $2 \mathrm{mmu}$ and thus adequately support the elemental compositions of these fragment ions as listed. There is more than one way that the fragment ions can be labeled using the Light/Kassel/Allison designation scheme. For example, the ion labeled $\left[\mathrm{HOS}_{3}^{-\mathrm{H}}\right] \mathrm{H}^{+}$could also be labeled $\left[\mathrm{HOS}_{3}^{+}\right]$; both designations have the same chemical formula but carry different implications in terms of the process by which the ion is actually formed (as will be discussed below). The structural assignments given in Table 1 for the fragment ions observed provide a starting point for discussing fragmentation pathways and may, of course, be altered as mechanistic information is obtained. Similar to the terminal glycosidic bond cleavage that leads to the ion at $m / z 651$, fragmentation occurs about the other two glycosidic bonds of digoxin followed by $\mathrm{H}$-shifts to produce $Y$ ions at $m / z 521,\left[\mathrm{AOS}_{1} \mathrm{OH}\right] \mathrm{H}^{+}$, and $m / z$ 391, $[\mathrm{AOH}] \mathrm{H}^{+}$. The ion at $\mathrm{m} / \mathrm{z} 391$ may also be $\left[\mathrm{HOS}_{3} \mathrm{OS}_{2} \mathrm{OS}_{1}^{-\mathrm{H}}\right] \mathrm{H}^{+}$. These assignments for the fragment ions based on the low resolution $F A B$ mass spectral data are confirmed by peak matching results, as presented in Table 1 . The two assignments for the ion current at $m / z 391$ will be discussed below.

Another type of ion formed in this experiment is represented by the ion at $m / z$ 633. This ion could be formed by cleavage of the $z$ bond instead of the $y$ bond in the terminal glycosidic bond, as designated in (1) to 

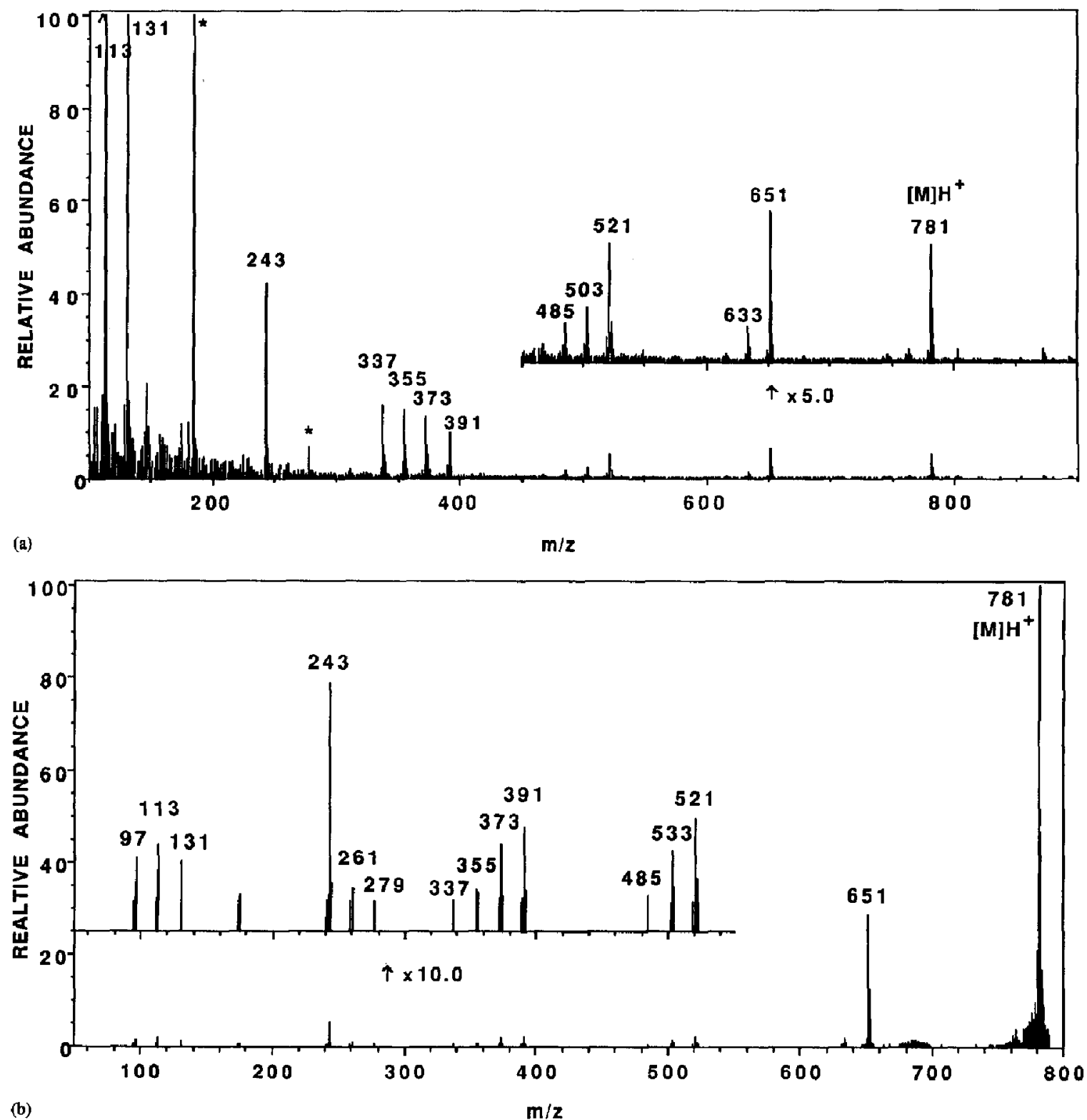

Figure 2. (a) The FAB mass spectrom of digoxin in glycerol. The glycerol adduct ions are laheled as *. (b) The linked scan CAD spectrum of the digoxin parent ion $[\mathrm{M}] \mathrm{H}^{+}$at $m / z 781$.

produce a $Z_{2}$ ion [9]. In this case the glycosidic oxygen remains with the nonreducing terminal sugar. This cleavage would produce two fragments with masses of

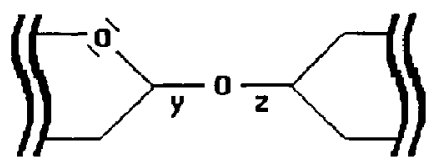

(I)
147 and $633 \mathrm{u}$. An $\mathrm{H}$-shift toward the glycosidic oxygen would produce two neutral species of masses 148 and $632 u$, respectively. Only one of these species is observed, in a protonated form, at $m / z$ 633, which may suggest that this ion is formed by loss of $\mathrm{H}_{2} \mathrm{O}$ from the ion at $m / z 651$ instead of involving an uncommon cleavage about the $\mathrm{z}$ glycosidic bond [10]. (The two $\mathrm{C}-\mathrm{O}$ bonds in glycosidic linkages are chemically distinct; they tend to fragment more readily at the nonreducing end of the bond for typical glycosides, such as is seen for the cardiac glycosides upon acid catalyzed 
Table 1. Digoxin fragment ions: possible assignments and peak matching results

\begin{tabular}{|c|c|c|c|c|}
\hline$m / z$ & Assignment & LKA $^{a}$ designation & $\mathrm{DC}^{\mathrm{b}}$ designation & $\Delta m m u^{c}$ \\
\hline 781 & $\mathrm{C}_{41}, \mathrm{H}_{65} \mathrm{O}_{14}^{+}$ & {$\left[\mathrm{AOS}_{1} \mathrm{OS}_{2} \mathrm{OS}_{3} \mathrm{OH}\right] \mathrm{H}^{+}:\left[\mathrm{MIH}^{+}\right.$} & {$[\mathbf{M}+\mathbf{H}]^{+}$} & -0.2 \\
\hline 651 & $\mathrm{C}_{35} \mathrm{H}_{55} \mathrm{O}_{11}^{+}$ & {$\left[\mathrm{AOS}_{1} \mathrm{OS}_{2} \mathrm{OH} \mathrm{H}^{+}\right.$} & $Y_{2}$ & +1.0 \\
\hline 633 & $\mathrm{C}_{35} \mathrm{H}_{53} \mathrm{O}_{10}^{+}$ & {$\left[\mathrm{AOS}_{1} \mathrm{OS}_{2} \mathrm{OH}-\mathrm{H}_{2} \mathrm{O} \mathrm{H}^{+}\right.$} & $z_{2}$ & -0.7 \\
\hline 521 & $\mathrm{C}_{29} \mathrm{H}_{46} \mathrm{O}_{8}^{+}$ & {$[\mathrm{AOS}, \mathrm{OH}] \mathrm{H}^{+}$} & $Y_{1}$ & -0.2 \\
\hline 503 & $\mathrm{C}_{29} \mathrm{H}_{43} \mathrm{O}_{7}^{+}$ & {$\left[\mathrm{AOS}, \mathrm{OH}-\mathrm{H}_{2} \mathrm{O}\right] \mathrm{H}^{+}$} & $\mathbf{Z}_{\uparrow}$ & +1.6 \\
\hline \multirow[t]{2}{*}{391} & $\mathrm{C}_{23} \mathrm{H}_{35} \mathrm{O}_{5}^{+}(81)^{d}$ & {$[\mathrm{AOH}] \mathrm{H}^{+}$} & $Y_{0}$ & -1.6 \\
\hline & $\mathrm{C}_{18} \mathrm{H}_{31} \mathrm{O}_{9}^{+}(19\}$ & {$\left[\mathrm{HOS}_{3} \mathrm{OS}_{2} \mathrm{OS}_{1}^{-H}\right] \mathrm{H}^{+}$} & $\mathrm{B}_{3}$ & 0.0 \\
\hline \multirow[t]{2}{*}{373} & $\mathrm{C}_{23} \mathrm{H}_{33} \mathrm{O}_{4}^{+}(59)$ & {$\left[\mathrm{AOH}-\mathrm{H}_{2} \mathrm{OlH}^{+}\right.$} & $z_{0}$ & -1.0 \\
\hline & $\mathrm{C}_{18} \mathrm{H}_{29} \mathrm{O}_{8}^{+}(41)$ & 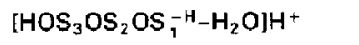 & $\mathrm{B}_{3}-\mathrm{H}_{2} \mathrm{O}$ & -0.6 \\
\hline \multirow[t]{2}{*}{355} & $\mathrm{C}_{23} \mathrm{H}_{31} \mathrm{O}_{3}^{+}(82)$ & {$\left[\mathrm{AOH}-2 \mathrm{H}_{2} \mathrm{O}\right] \mathrm{H}^{\prime}$} & $\mathrm{Z}_{0}-\mathrm{H}_{2} \mathrm{O}$ & -1.5 \\
\hline & $\mathrm{C}_{18} \mathrm{H}_{27} \mathrm{O}_{7}^{+}(18)$ & {$\left[\mathrm{HOS}_{3} \mathrm{OS}_{2} \mathrm{OS}_{1}^{-H}-2 \mathrm{H}_{2} \mathrm{O}\right] \mathrm{H}^{+}$} & $\mathrm{B}_{3}-2 \mathrm{H}_{2} \mathrm{O}$ & e \\
\hline \multirow[t]{2}{*}{337} & $\mathrm{C}_{23} \mathrm{H}_{29} \mathrm{O}_{2}^{+}(76)$ & {$\left[\mathrm{AOH}-3 \mathrm{H}_{2} \mathrm{O}\right]^{+}$} & $\mathrm{Z}_{0}-2 \mathrm{H}_{2} \mathrm{O}$ & -1.0 \\
\hline & $\mathrm{C}_{18} \mathrm{H}_{25} \mathrm{O}_{6}^{+}(24)$ & 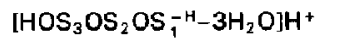 & $\mathrm{B}_{3}-3 \mathrm{H}_{2} \mathrm{O}$ & +0.9 \\
\hline 243 & $\mathrm{C}_{12} \mathrm{H}_{19} \mathrm{O}_{5}^{+}$ & $\mathrm{LHOS}_{3} \mathrm{OS}_{2}^{-\mathrm{H}}-\mathrm{H}_{2} \mathrm{OlH} \mathrm{H}^{+}$ & $\mathrm{B}_{2}-\mathrm{H}_{2} \mathrm{O}$ & +2.2 \\
\hline 131 & $\mathrm{C}_{6} \mathrm{H}_{11} \mathrm{O}_{3}^{+}$ & {$\left[\mathrm{HOS}_{3}^{-\mathrm{H}}\right] \mathrm{H}^{+}$} & $\mathrm{B}_{1}$ & -0.6 \\
\hline 113 & $\mathrm{C}_{6} \mathrm{H}_{9} \mathrm{O}_{2}^{+}$ & $\mathrm{IHOS}_{3}^{-\mathrm{H}}-\mathrm{H}_{2} \mathrm{OJ} \mathrm{H}^{+}$ & $\mathrm{B}_{1}-\mathrm{H}_{2} \mathrm{O}$ & -0.2 \\
\hline 97 & $\mathrm{C}_{6} \mathrm{H}_{9} \mathrm{O}^{+}$ & {$\left[\mathrm{S}-\mathrm{H}_{2} \mathrm{O}\right] \mathrm{H}^{+}$} & $?$ & +0.3 \\
\hline
\end{tabular}

hydrolysis. See, for example, ref 10.$)$ This presents a question as to how to designate the ion at $m / z 633$ until the mechanism is determined. It could be labeled as $\left[\mathrm{AOS}_{1} \mathrm{OS}_{2}^{-H}\right] \mathrm{H}^{+}$or $\left[\mathrm{AOS}_{1} \mathrm{OS}_{2} \mathrm{OH}-\mathrm{H}_{2} \mathrm{O}\right] \mathrm{H}^{+}$. The first designation suggests its formation via a one step process; by cleavage of the $z$ bond, whereas the second notation carries no implication concerning the site of $\mathrm{H}_{2} \mathrm{O}$ loss, but does connote a two-step process. Obviously, information on the fragmentation pathway is required to determine which of these two designations is most appropriate. However, most fragment ions observed in the spectra of glycosides appear to be formed by cleavage of the $y$ glycosidic bond with retention of the glycosidic oxygen on the reducing portion of the molecule (containing the aglycone), accompanied by an H-shift toward this glycosidic oxygen [9]. If this cleavage (to produce $Y$ ions) is most prevalent for digoxin, then the ion at $m / z 633$ is most probably formed by the loss of $\mathrm{H}_{2} \mathrm{O}$ from either the aglycone or one of the sugars in the ion observed at $m / z 651$.

The final type of ions is in the $300 \mathrm{u}$ range that begins with $m / z$ 391, wilh a series of ions 18 u lower, at $m / z 373,355$, and 337 , which do not simply correlate with primary fragments of the molecule (as in the discussion above), and must be the result of multiple dehydration steps. The ion at $m / z 391$ has two possible identities due to the nearly symmetric nature of this molecule (in terms of mass). Cleavage of the $\mathrm{AO}-\mathrm{S}_{1}$ glycosidic bond in the neutral digoxin molecule followed by an H-shift toward the aglycone would produce two neutral species, each with a mass of 390 , both of which could appear in the mass spectrum in the protonated form at $m / z$ 391. Peak matching results are vital for this group of ions that can each have two possible origins. Without knowing the exact composition of this mass spectral peak with a nominal mass of 391, it would be impossible to discuss the fragmentation mechanism(s) involved. The exact masses of the aglycone structure and sugar portion differ by approximately $50 \mathrm{mmu}$, and thus peak matching and/or high resolution scanning can be used to determine the contribution to each peak from the aglycone portion and the contribution from the sugar portion of the molecule. Peak matching results are presented in Table 1 and the deviations of experimentally obtained exact masses from calculated exact mass determinations are all within $2 \mathrm{mmu}$. These results indicate that the ions in the $300 \mathrm{u}$ range each have two components, one from each end of the molecule. The contribution to the peak at $m / z 355$ from the sugar portion could be detected, but that signal is too weak to allow an accurate mass measurement. The relative contributions, from the aglycone portion and the sugar portion of the molecule, within these doublet peaks, do vary throughout the series of $300 \mathrm{u}$ range ions. High resolution scanning is used to determine the relative contributions of each component to the ion current of each nominal mass. The results of three experiments of high resolution scanning for the ions at $m / z 391, m / z 373, m / z 355$, and $m / z 337$ were 
Table 2. Relative intensity data from the CAD mass spectra of digoxin fragment ions

\begin{tabular}{|c|c|c|c|c|c|c|c|c|c|c|c|c|}
\hline \multicolumn{13}{|c|}{ Parent ions (nominal mass) ${ }^{a}$} \\
\hline & 781 & 651 & 633 & 521 & 503 & 391 & 373 & 355 & 337 & 243 & 131 & 113 \\
\hline \multicolumn{13}{|c|}{$\begin{array}{l}\text { Daughter ions } \\
\text { (nominal mass) }\end{array}$} \\
\hline $\begin{array}{l}763 \\
651\end{array}$ & $\begin{array}{r}3.9 \\
280\end{array}$ & & & & & & & & & & & \\
\hline $\begin{array}{l}651 \\
633\end{array}$ & $\begin{array}{r}28.9 \\
1.9\end{array}$ & 2.8 & & & & & & & & & & \\
\hline 615 & & 0.6 & 4.3 & & & & & & & & & \\
\hline 521 & 2.4 & 6.8 & 23.7 & & & & & & & & & \\
\hline 503 & 1.8 & 1.4 & 12.2 & 5.3 & & & & & & & & \\
\hline 485 & 0.8 & 1.6 & 2.8 & 2.4 & 7.8 & & & & & & & \\
\hline 467 & & 0.4 & & 0.7 & 2.6 & & & & & & & \\
\hline 391 & 2.2 & 3.3 & 5.1 & 4.4 & 31.2 & & & & & & & \\
\hline 373 & 1.9 & 2.3 & 2.9 & 5.4 & 6.9 & 8.0 & & & & & & \\
\hline 355 & 0.9 & 1.3 & 2.0 & 3.5 & 6.0 & 5.9 & 19.3 & & & & & \\
\hline 337 & 0.7 & 0.5 & & 1.0 & 1.7 & 0.8 & 5.8 & 23.6 & & & & \\
\hline 319 & & & & & & & & 0.6 & 2.2 & & & \\
\hline 279 & & & & & & 0.6 & & & & & & \\
\hline 261 & 1.0 & & & & & 0.6 & 0.4 & 0.5 & & & & \\
\hline 243 & 5.4 & 3.1 & 9.4 & & & 0.6 & 1.3 & 0.6 & 1.0 & & & \\
\hline 225 & & & 1.3 & & & 0.2 & 0.4 & 0.5 & & 1.0 & & \\
\hline 149 & & & & & & 0.2 & & & & 0.9 & & \\
\hline 131 & 1.5 & 1.5 & 2.0 & 1.8 & 1.2 & 0.3 & 0.4 & & & 0.7 & & \\
\hline 113 & 1.9 & 1.4 & 2.4 & 1.2 & 2.3 & 0.3 & 0.4 & & & 0.3 & 4.9 & \\
\hline 97 & 1.6 & 0.8 & 1.2 & & & 0.3 & 10.5 & 0.3 & & 9.3 & & 0.1 \\
\hline 95 & 0.7 & & & & & 0.2 & & & & & & 2.0 \\
\hline 85 & & & & & & & & & & & & 0.4 \\
\hline 83 & & & & & & & & & & & 0.1 & 0.2 \\
\hline 69 & & & & & & & & & & & 0.6 & 0.5 \\
\hline$\Sigma$ & 59 & 28 & 69 & 26 & 60 & 18 & 39 & 26 & 3 & 12 & 6 & 3 \\
\hline
\end{tabular}

- Parent ions are the $[\mathrm{M}] \mathrm{H}^{+}$and the fragment ions observed in the $F A B$ mass spectrum of digoxin.

averaged and the percent contribution of each component is presented in Table 1 . These ratios vary somewhat with experimental conditions, such as ion source pressure, which may suggest that some fragmentation occurs as CAD within the ion source. In most cases, the contribution to each doublet peak is greater from the aglycone portion of the molecule than from the sugar portion. The peak at $m / z 373$ contains the largest contribution to the ion current from the sugar portion of the molecule than any of the other 300 u-range ions.

One case where low resolution mass spectrometry and peak matching capabilities are insufficient to suggest, unambiguously, a relationship between the $m / 2$ value of a fragment ion and some substructural feature of the original molecule is the ion at $m / z 243$. Based on the nominal mass assignments and peak matching, it is determined that this ion is from the sugar portion of the molecule but could have one of two assign-

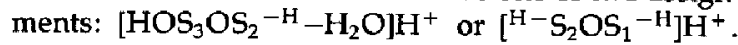
This ion also appears as a daughter ion from CAD analyses of all of the fragment ions that contain at least two sugars. In an attempt to differentiate between these two assignments, the FAB spectrum of a similar compound was obtained. Acetyldigitoxin (structure F, Figure 1) was chosen for study because of its similar- ity to digoxin with two exceptions: the aglycone contains one less $\mathrm{OH}$ group (like digitoxin) and, more important, the terminal sugar contains an acetyl group. The ion observed at $m / z 243$ in the FAB mass spectrum of digoxin does shift to $m / z 285$ for acetyldigitoxin and suggests that this ion contains the terminal sugar where the acetyl group is located. Therefore, we will assume that the assignment for $m / z 243$, $\left[\mathrm{HOS}_{3} \mathrm{OS}_{2}{ }^{-\mathrm{H}}-\mathrm{H}_{2} \mathrm{O}\right] \mathrm{H}^{+}$, is correct and is included in Table 1.

Linked scan mass spectral data on ions formed from digoxin in the fast atom bombardment mass spectrum. In addition to the peak matching information, the linked scan CAD mass spectra of the parent ion $[\mathrm{M}] \mathrm{H}^{+}$and the major fragment ions of digoxin were obtained to provide additional information that may aid in the elucidation of fragmentation mechanisms. The results from these $\mathrm{CAD}$ experiments are presented in Table 2.

One difficulty with the $B / E$ linked scan technique performed on a forward geometry double-focusing mass spectrometer is that the resolution of the parent ion selection is low [11]. In practice, the acceptance window for the parent ion selection is approximately $5 \mathbf{u}$ wide. Therefore, the CAD spectra of the doublet 


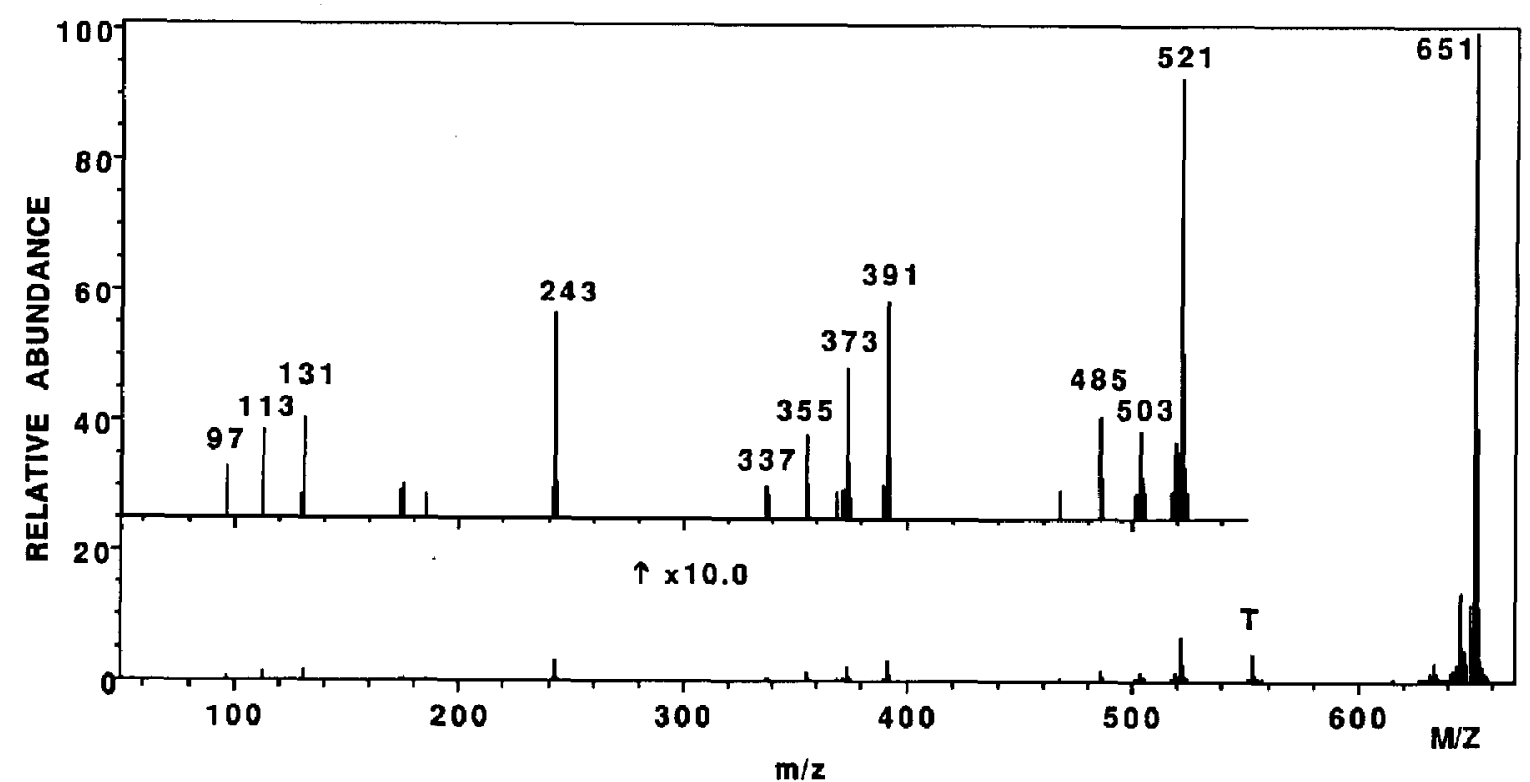

Figure 3. The linked scan CAD spectrum of the digoxin fragment ion at $m / z 651$. The peaks labeled $T$ are glycerol interferents that are present due to the glycerol cluster ion $6 \mathrm{u}$ from the parent ion at $\mathrm{m} / \mathrm{z} 651$ (see text).

ions, such as those at $m / z 373$, will contain a mixture of daughter ions from both of the isomass species. Also, this wide parent ion selection window can lead to artifact peaks from glycerol cluster ions (if glycerol is the matrix) when the $m / z$ value of the desired parent ion is within approximately $5 \mathrm{u}$ of a glycerol cluster ion.

The CAD mass spectrum of the $[\mathrm{M}] \mathrm{H}^{+}$ion is presented in Figure $2 \mathrm{~b}$ and that for the fragment ion at $m / z 651$ is shown in Figure 3 as an example of the linked scan spectra obtained for the major fragment ions of digoxin. The two spectra in Figures $2 \mathrm{~b}$ and 3 are very similar in appearance and content even though the two parent ions differ by one sugar. To obtain these linked scan data, the helium collision gas pressure was set to produce a $10 \%$ attenuation of the $[\mathrm{M}] \mathrm{H}^{+}$ion and was maintained at this same pressure to obtain the CAD linked scan spectra of the major fragment ions of digoxin. The results of these $C A D$ experiments, the daughter ion $\mathrm{m} / \mathrm{z}$ values and relative abundances, for all of the major fragment ions of digoxin are listed in Tablc 2 . These relative abundances are from the normalization of the fragment ion currents to that of the parent ion. Therefore, the absence or presence of the daughter ions and their relative abundances can be compared within each $\mathrm{B} / \mathrm{E}$ linked scan, but the abundances between linked scans for different parent ions should not be compared directly. The last row in Table 2 contains the sum of the relative abundances of all fragment ions produced from each selected parent ion (the sum of the columns) and gives some measure of the relative extent of fragmentation that occurs upon CAD of each species.
One ion not listed in this table is that at $m / z 175$. This fragment ion is not observed as a daughter ion in the majority of the linked scan spectra collected. This ion is believed to originate from a ring fragmentation of the middle sugar, referred to as an $A_{3}$ cleavage, using the Domon/Costello nomenclature. According to Domon and Costello [9], this ring cleavage is not common in the $\mathrm{FAB}$ analysis of saccharide-containing compounds in the positive ion mode. This ion at $\mathrm{m} / \mathrm{z}$ 175 is the only ring cleavage product observed in these studies.

\section{Discussion}

Before evaluating the data in search of clues to the fragmentation mechanisms that may be operative for protonated digoxin, a discussion of some of the likely mechanistic possibilities will be presented. When considering mechanisms, one can certainly benefit from the approach used by McLafferty [1] in the context of fragment ions formed by EI. One should first consider the description of the ionized molecule (where are the charge/radical sites?), then propose possible fragmentations based on established mechanisms and chemical intuition. In the case of a protonated molecule, an even electron ion, the literature on chemical ionization $(\mathrm{CI})$ mass spectrometry [12] certainly provides a useful framework. Thus, we first ask the question concerning the nature of the protonated molecule produced by FAB. Where is it protonated [13]? (We note that much work has been done to investigate the site of protonation in molecules that contain more than one basic site. See, for example, ref 13.) It is difficult to an- 


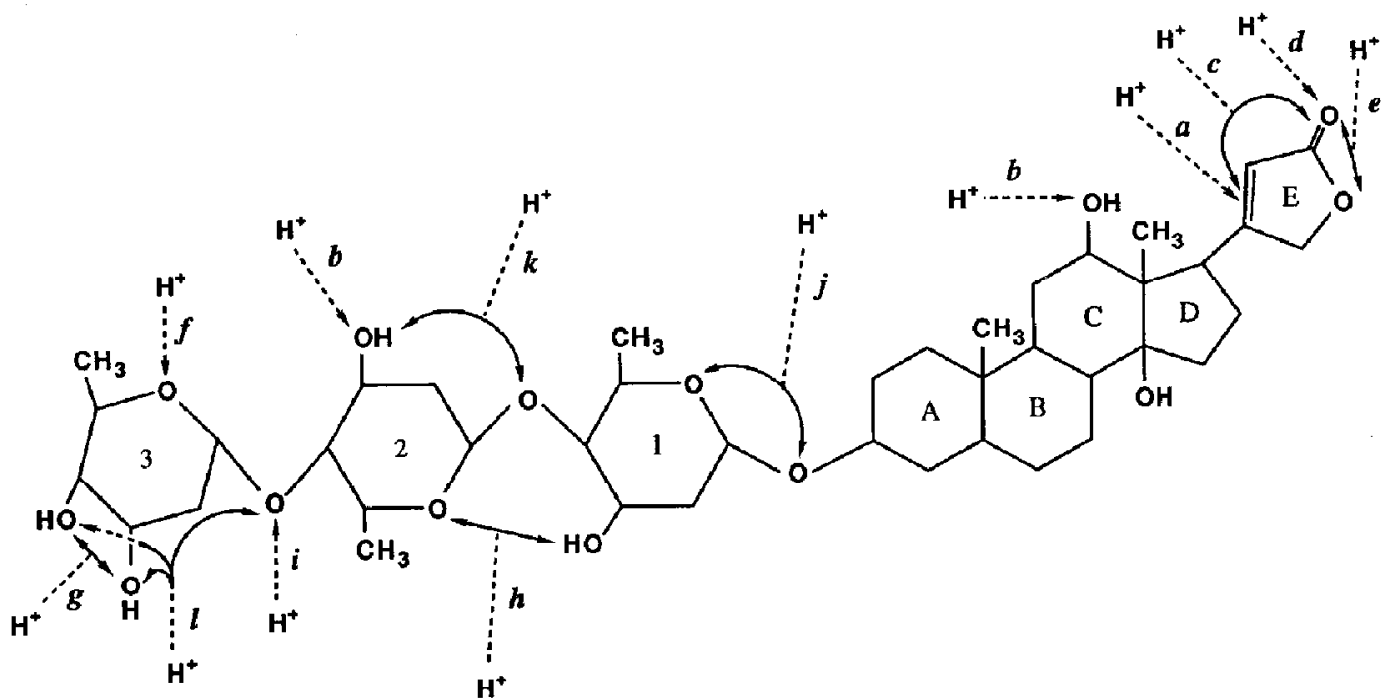

Figure 4. Extended structure of digoxin based on crystallographic data with possible sites of protonation labeled $a$ through $l$.

swer this question for many reasons. We do not know how the molecule is protonated. It presumably occurs by gas phase proton transfer [3] from protonated glycerol and/or some fragment ion derived from glycerol such as $m / z$ 45. It is probable that protonation of any of the heteroatoms in the molecule could occur because the proton transfer is probably from an oxygencontaining Lewis base to one of the oxygen atoms in the cardiac glycoside. There are many different types of sites on the digoxin molecule with different proton affinities. An extended structure of digoxin, based on the crystallographic analysis of the molecule [14], is presented in Figure 4 with possible protonation sites indicated. We have estimated the proton affinities of these sites, labeled $a$ through $l$ in Figure 4 , and these values are presented in Figure 5. The proton affinities of the different sites on digoxin are approximated based on smaller compounds, resembling these sites, whose proton affinities are known [15]. In those cases where there are multiple interactions, estimates for the increase in proton affinity (PA) due to secondary interactions have been made and are discussed in Appendix 1. Based on the estimates in Figure 5, it appears that many of the possible sites of protonation of the digoxin molecule lie in the PA range of 190-200 $\mathrm{kcal} / \mathrm{mol}$. Also shown in Figure 5 are possible protonating species derived from glycerol. Candidates as protonating reagent ions are selected based on the FAB mass spectrum of glycerol reported by Sunner et al. [3], which includes the protonated glycerol molecule and lower mass glycerol fragments. Note that all of the glycerol fragments have proton affinities lower than that of glycerol, $209 \mathrm{kcal} / \mathrm{mol}$ [3]. If the PA values in Figure 5 are correct, proton transfer from protonated glycerol to most of the labeled sites of digoxin would be endothermic, however, proton transfer from the fragment ions of glycerol is possible. The most basic sites in the molecule appear to be the glycosidic linkages, which are further enhanced by additional interactions. It has been shown that protonated molecules containing two functional groups can show intramolec ular hydrogen bonding, even when the two groups are separated by many methylene groups. Frequently, $10-20 \mathrm{kcal} / \mathrm{mol}$ can be introduced by such secondary interactions [16]. We propose that the site of highest

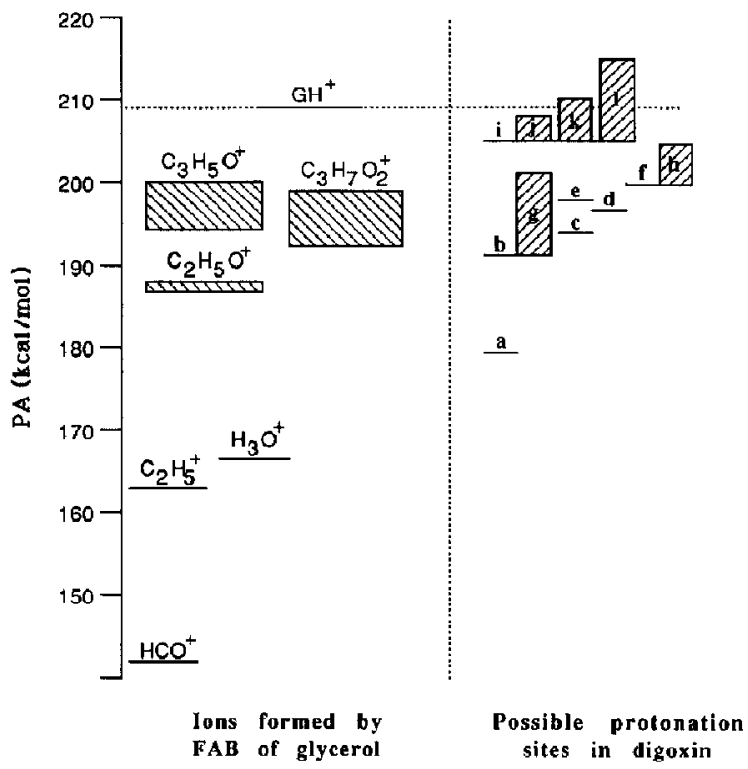

Figure 5. Estimates of the proton affinities of the basic sites labeled on the digoxin structure in the figure and estimates of the proton affinities of possible protonating agents from glycerol and glycerol fragments. 
PA is the terminal sugar unit. The basic site formed by the two $-\mathrm{OH}$ groups plus the $-\mathrm{OR}$ group, all three being on the same side of the ring, resembles the interactions described by Winkler and McLafferty [17] for a protonated cyclohexanetriol. In digoxin (solid), the ring oxygen of sugar 2 is in close proximity to the $\mathrm{OH}$ group in the 3 position on sugar 1, making site $h$ a possible site for a multiple interaction. Our conclusion is that any part of the molecule may be protonated in the FAB experiment with a glycerol matrix, although not necessarily by the most abundant of the possibte candidates from glycerol, [glycerol] $\mathrm{H}^{+}$.

How, then, should we consider the protonated molecule in the context of the fragmentation that will follow protonation? In this regard, two extremes have been discussed in the literature. In the simplest approach, the molecule is protonated and fragmentation follows directly, occurring at that protonation site [18]. For example, it has been proposed that protonated bradykinin, formed by field desorption, fragments at the site of protonation and the proton does not migrate freely about the molecule [19]. The other extreme is a dynamic model that suggests that the initial site of protonation would be, in this case, irrelevant-the proton rapidly moves from heteroatom to heteroatom, with the possibility of fragmentation occurring at every site while the proton resides at that site [20]. We believe that the latter is more likely in this case, and will assume that our starting point will be a protonated molecule that has a mobile proton.

What possible fragmentation mechanisms may be operative for this even electron ion? Mechanisms that have been proposed include inductive cleavage processes, fragmentation involving multiple bond cleavages (1,2-elimination reactions and ring cleavage processes), and remote site fragmentations.

\section{Inductive Cleavage}

Domon and Costello [9] have proposed a scheme for naming fragment ions from carbohydrates, and the process that they have proposed leading to what they call $B_{i}$ ions is shown in reaction 1 for two digitoxose sugars.
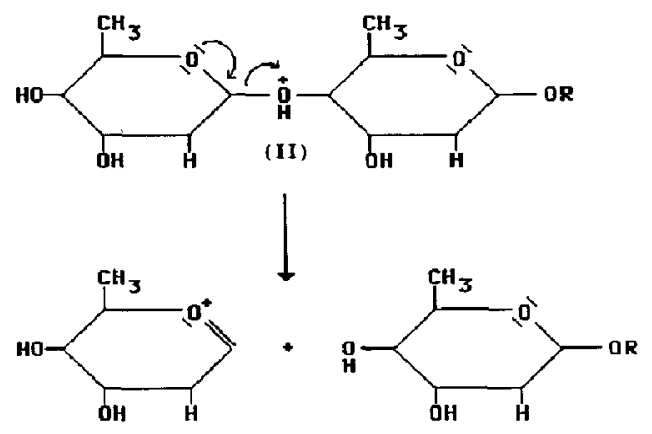

(III)
Inductive effects lead to cleavage of the glycosidic bond at the site of protonation in (II), forming the charge migration product (III). It has certainly been documented that inductive processes involving oxygen do readily occur [1], and such a mechanism is reasonable for this even-electron ion (II).

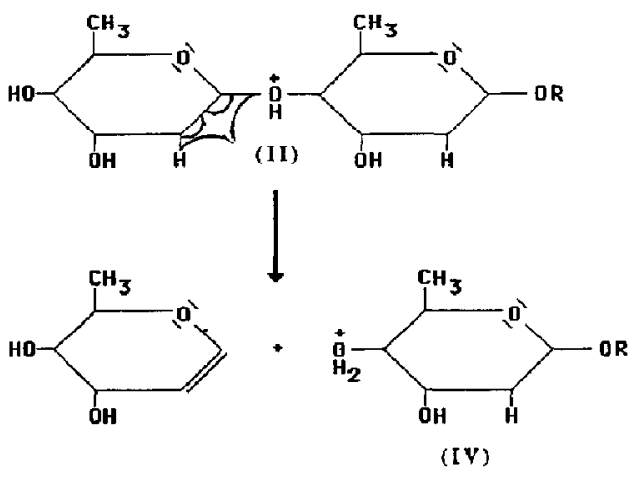

\section{Multiple Bond Cleavage Processes}

We will not discuss ring cleavage reactions because only one has, possibly, been observed in this study (at $m / z$ 175). However, it is apparent that $\mathrm{H}$-shifts do occur, and accompany glycosidic $\mathrm{C}-\mathrm{O}$ cleavages. For example, reaction 2 has been proposed by Domon and Costello [9] to yield $Y_{i}$ ions, of the type (IV). The mechanism suggests a 1,2-elimination to leave a double bond in the neutral sugar fragment, although $\mathrm{H}$ shifts from other sites within the molecule cannot be ruled out [21]. (H-shifts in peptides as 1,2-eliminations have been proposed in refs 19 and 21a. H-shifts in peptides as 1,3-eliminations have been proposed in ref $21 \mathrm{~b}$. Hshifts via 7 and 8 -membered rings have been discussed in ref 21c.) Thus, the fragment ions (III) and (IV) are proposed to come from a common intermediate, (II), via two different mechanisms. It is also possible that the fragment ions (III) and (IV) are formed through another common intermediate and a single mechanistic step. This is shown in reaction 3 . The starting point is an ion of the type (II), protonated on a glycosidic oxygen. The charge site stimulates a 1,2-elimination reaction to form the proton-bound adduct shown as (V), which can then dissociate to form either (VI) and/or (VII), depending on which fragment retains the proton. (This mechanism is similar to that suggested by Stevenson's rule [1] in EI, in which separating fragments compete for the charge; here the competition is for the proton. This protic analogy to Stevenson's rule has not been established to date, although it has been alluded to by Bowen et al [22].) Thus, the ions of that type labeled (III) and (VI) are the same, except that (VI) is formed via an H-shift. It is difficult to decide on a designation for such ions. In our nomenclature scheme, the two different mechanisms would suggest that an ion such as that shown as (VI) could be labeled as $\mathrm{HOS}_{3} \mathrm{OS}_{2}{ }^{+}$or $\left[\mathrm{HOS}_{3} \mathrm{OS}_{2}{ }^{-\mathrm{H}}\right] \mathrm{H}^{+}$, and we have ten- 

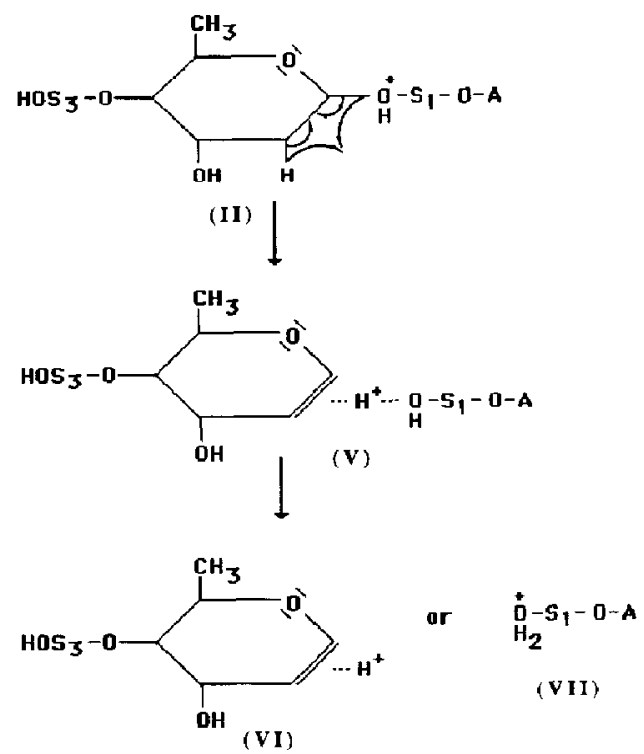

tatively chosen the latter. It is also interesting to note that while Domon and Costello [9] have proposed reaction 2, they write the product not as (IV) but as (VIII), in which the proton in this fragment ion has moved from its initial site on the terminal hydroxy group in (IV) to another glycosidic linkage; presumably this was done to suggest that the proton is mobile following protonation.

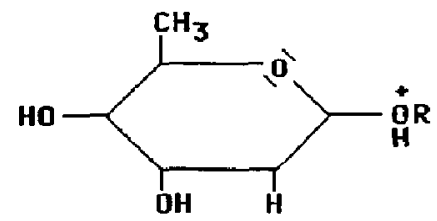

(VIII)

\section{Remote Site Fragmentation}

Jensen et al. [23], Adams [24], and Wysocki et al. [25] discussed the remote site mechanism in ions for which the charge and/or radical site are apparently far from the site of fragmentation. Such mechanisms certainly seem reasonable when a $\mathrm{C}-\mathrm{C}$ bond is broken in a long alkyl chain of an ion containing a single functional group, and difficult to prove for multifunctional molecules. This mechanism would suggest that protonation can occur at any part of the molecule, and fragmentation need not be local to the site of protonation. Vine et al. [26] discussed the possibility of remote site fragmentation occurring in the ammonia $\mathrm{CI}$ mass spectra of cardiac glycosides. They suggest that the ammonium ion may complex with the aglycone portion of the molecule and 1,2-eliminations about the glycosidic linkage may occur far from this site, as
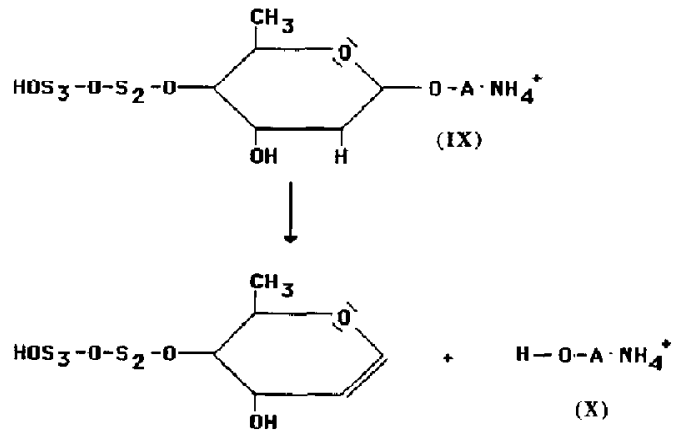

shown in reaction 4 . It is interesting to note that in a recent article on the mass spectrometry of peptides by Johnson et al. [21a], it was proposed that much of the fragmentation observed for peptides may occur via remote site processes.

Adams and Gross [27] have discussed the analogy of remote site fragmentations to thermolytic processes. Energy is imparted into the molecular ion, which fragments as it would if energy were added to the corresponding neutral molecule. In this context, we have reported the $K^{+}$IDS mass spectrometric analysis of cardiac glycosides [8]. $\mathrm{K}^{+} \mathrm{IDS}, \mathrm{K}^{+}$ionization of desorbed species, is a technique that combines rapid thermal processes, thermal degradation, and vaporization, with gas phase $\mathrm{K}^{+}$attachment. We note that when digoxin is rapidly heated, 1,2-eliminations appear to readily occur about the glycosidic bonds, yielding $\mathrm{K}^{+}$adducts that are very similar to those seen here in protonated form. In $\mathrm{K}^{+}$IDS, decomposition occurs before $\mathrm{K}^{+}$attachment $\left(\mathrm{K}^{+}\right.$attachment does not induce much fragmentation), while in FAB protonation presumably precedes decomposition and often induces fragmentation. Even with these differences in fragmentation processes, preceding ionization in $\mathrm{K}^{+} \mathrm{IDS}$ and following ionization in FAB, most of the same fragmentation processes are observed in both mass spectra. The correlation between the FAB and $\mathrm{K}^{+}$IDS spectra could be fortuitous, but may support remote site processes that are not initiated by the charge site but rather by energy deposition in general.

Mechanistic discussions of FAB presented here are based on the assumption that protonation of the intact molecule precedes fragmentation. However, it is possible that direct fragment ion formation from the matrix upon bombardment can occur. Many of the fragment ions of digoxin contain the aglycone. However, there are some ions in the low mass range that are from the sugar portion of the molecule. Two such ions are at $m / z 113$ and 131 from the terminal sugar (Table 1) and are the most abundant fragment ions in the FAB mass spectrum (Figure 2a) of the digoxin sample. Additional experiments were performed to investigate the origin of these two abundant low mass ions. The FAB mass spectra of digoxin in glycerol were collected and monitored for a period of thirty minutes. 
During this time the ions at $m / z 113$ and $m / z 131$ remained dominant, even when only a trace of glycerol remained and the $\left[{\mathrm{M}] \mathrm{H}^{+}}^{+}\right.$ion of digoxin was no longer observed. These two low mass ions seem to be formed, at least to some extent, in a different manner than the $[\mathrm{M}] \mathrm{H}^{+}$ion. It is possible, based on the observations of this extended FAB experiment, that these two low mass sugar ions may be formed directly from the liquid target upon bombardment and are not only the

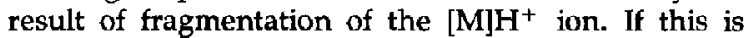
the case, then the decomposition of the $[\mathrm{M}] \mathrm{H}^{+}$ion of digoxin produces predominantly daughter ions that contain the aglycone. The ions from the sugar portion that do not contain the aglycone may be formed by other ionization/fragmentation processes.

The mechanisms discussed here must be evaluated with experimental data in order to determine the most probable fragmentation pathways. We now turn to the peak matching and linked scan data to determine whether these results support any of the mechanisms discussed, or suggest others.

\section{Discussion of Collisionally Activated Dissociation Data}

Analysis of the CAD data should provide some insights into the fragment ion structures and, from these, insights into the mechanisms through which they are formed. The mechanisms proposed above that are based on a localized site of protonation in the molecule, leading to fragmentation at the site of protonation, would be substantiated by a CAD mass spectrum of a fragment ion with very few daughter ions produced. If the site of protonation is also the site of fragmentation and the charge site does not migrate, then the primary fragment [with a structure such as (IV)] might be expected to only undergo $\mathrm{H}_{2} \mathrm{O}$ losses with no extensive fragmentation upon CAD. Other types of fragmentation mechanisms, where the charge is mobile throughout the molecule or is localized followed by remote fragmentation, may produce more extensive fragmentation of the parent species upon CAD. Substructure-specific daughter ions may be formed, and this concept will be used here. Suppose an ion is observed $18 \mathrm{u}$ below another fragment ion due to a water loss, for example, the ion at $m / z 633,18 \mathrm{u}$ below the major fragment ion at $m / z$ 651. From where was the water lost? The ion at $m / z 651,\left[\mathrm{AOS}_{1} \mathrm{OS}_{2} \mathrm{OH}\right] \mathrm{H}^{+}$, could eliminate water from the terminal sugar $\left(S_{2}\right)$, the interior sugar $\left(S_{1}\right)$, or from the aglycone $(A)$. If there is a daughter ion present in the CAD mass spectrum of $m / z 633$ that represents the loss of an intact sugar, a neutral loss of $130,\left[\mathrm{HOS}_{2}{ }^{-\mathrm{H}}\right]$, then the water elimination cannot be from the terminal sugar. However, if a neutral loss of $112,\left[\mathrm{HOS}_{2}-\mathrm{H}-\mathrm{H}_{2} \mathrm{O}\right]$, is observed in the absence of a 130 loss, this would suggest that the terminal sugar in $m / z 651$ was the site of $\mathrm{H}_{2} \mathrm{O}$ loss. This neutral loss prediction is shown in Figure 6 and is

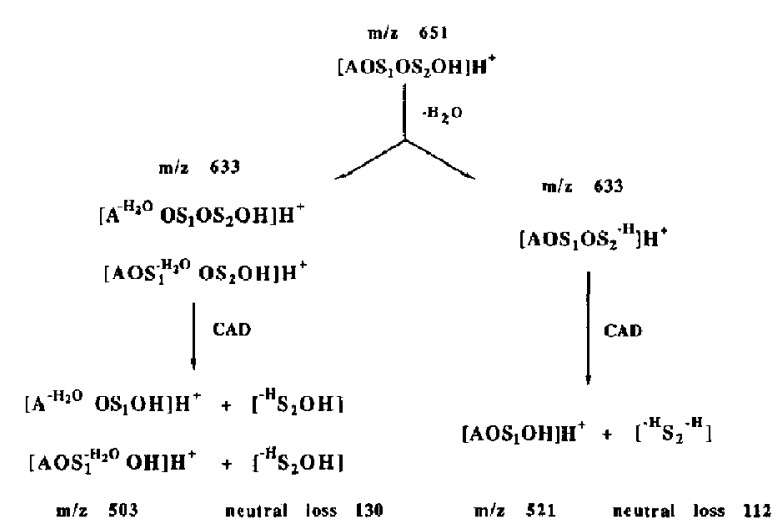

Figure 6. Schematic diagram of the $\mathrm{H}_{2} \mathrm{O}$ losses from $m / z 651$ that can occur to produce the ion at $m / z$ 633. Neutral losses observed from the CAD of $m / z 633$ can help determine the structure of the ions at $m / z 633$.

explained in more detail in the discussion of the CAD results for the ion at $m / z$ 633. In a similar fashion, one could search for ions indicative of the intact aglycone, which would indicate that the $\mathrm{H}_{2} \mathrm{O}$ loss is not from that portion of the selected parent ion. These types of observations and conclusions are presented here for the CAD data obtained for the fragment ions formed in the FAB analysis of digoxin.

Collisionally activated dissociation of $m / z$ 781. The discussion of the data begins with the $[\mathrm{M}] \mathrm{H}^{+}$ion of digoxin at $m / z 781$. The daughter ions of the protonated molecule are very similar to those observed in the FAB mass spectrum of digoxin except for some relative abundance variations of the fragment ions. The same fragment ions appear in both the FAB mass spectrum of digoxin (Figure 2a) and the CAD mass spectrum of the protonated molecule (Figure $2 b$ ). This observation is consistent with the desorption ionization mechanism that is assumed to be operative here, that is, the fragment ions observed in the FAB spectrum of this neutral analyte are from unimolecular decomposition of the protonated, intact, molecule as opposed to being fragments that are emerging directly from the target upon FAB. There are some differences between these two spectra, notably that the FAB mass spectrum shows a more abundant $\left[\mathrm{M}-\mathrm{H}_{2} \mathrm{O}\right] \mathrm{H}^{+}$ion than the $\mathrm{B} / \mathrm{E}$ mass spectrum. Also, the dominant ions from the FAB analysis of digoxin are at $m / z 113$ and $m / z 131$ and are less abundant in the linked scan mass spectrum of the $[\mathrm{M}] \mathrm{H}^{+}$ion. An explanation is suggested from the data in Figure 5. There exists in the selvedge region of the FAB experiment a collection of reagent ions available for proton transfer in the $m / z$ range 19-93. Of these, the most abundant is protonated glycerol at $m / z$, which may only be able to protonate the most basic site $(l)$. on the terminal sugar, leading to prompt formation of $m / z 131$ and $m / z$ 113, and a large abundance 
of these ions. The lower mass reagent ions protonate other parts of the digoxin molecule, and many of these $[\mathrm{M}] \mathrm{H}^{+}$ions are sufficiently long lived to be observed in the FAB mass spectrum at $m / z$ 781. These latter ions are the ones chosen for CAD analysis.

Collisionally activated dissociation of $m / z$ 651. A major fragment ion of digoxin is observed at $m / z 651$ in the FAB mass spectrum. It is also the most abundant

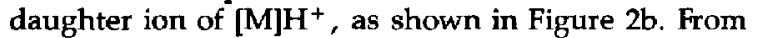
the peak matching results it is proposed that the structure of this ion corresponds to a protonated cardiac glycoside containing only two sugars (see Table 1 ). The daughter spectrum of $m / z$ 651, shown in Figure 3, closely resembles that of the $[\mathrm{M}] \mathrm{H}^{+}$species of digoxin, shown in Figure $2 b$. If the mechanism of fragmentation to produce the ion at $m / z 651$ were charge initiated as shown in reaction 2 , then the CAD mass spectrum of $m / z 651$ should be very simple with daughter ions at $m / z$ [651-18]. Instead, the CAD mass spectrum closely resembles that of the $[\mathrm{M}] \mathrm{H}^{+}$ion and is what would be expected for a CAD mass spectrum of a protonated cardiac glycoside containing two sugars, $\left[\mathrm{AOS}_{1} \mathrm{OS}_{2} \mathrm{OH}\right] \mathrm{H}^{+}$. If the mechanism of reaction 2 is operative, the proton must be mobile and not localized in the product. This requirement of proton mobility to explain the extensive subsequent fragmentation of primary fragments undergoing CAD was presumably recogrized by Domon and Costello [9] when they chose the specific designation shown as structure (VIII), with the proton moving within the ion following fragmentation. The neutral loss of 130 from the parent ion at $m / z 651$ yielding $m / z 521$ further supports the structural assignment of $m / z 651$, as this requires that the terminal sugar must be intact, without any $\mathrm{H}_{2} \mathrm{O}$ losses. One fragment ion of $m / z 651$, at $m / z 467$, is not observed in the linked scan mass spectrum of the $[\mathrm{M}] \mathrm{H}^{+}$ion. A possible explanation for the presence of this daughter ion in the CAD mass spectrum of $\mathrm{m} / \mathrm{z}$ 651 is as follows. Both parent species at $m / z 781$ and $m / z 651$ can form the daughter ion at $m / z 521$, which is [ $\left.\mathrm{AOS}_{1} \mathrm{OH}\right] \mathrm{H}^{+}$. In the CAD of $m / z 781$, the fragment at $m / z 521$ loses one and two $\mathrm{H}_{2} \mathrm{Os}$ to yield ions at $m / z 503$ and $m / z 485$. In the B/E spectrum of $m / z 651$, the fragment at $m / z 521$ is formed to a greater extent, and therefore may allow for the observation of up to three $\mathrm{H}_{2} \mathrm{O}$ losses, at $m / z 503, m / z 485$, and $m / z 467$. The sugar component of $m / z 521$ can only lose two of these water molecules as there are only two $-\mathrm{OH}$ groups on the sugar, and likewise for the aglycone portion, which has only two $-\mathrm{OH}$ groups. Therefore, these multiple $\mathrm{H}_{2} \mathrm{O}$ eliminations from $m / z 521$ must occur throughout the $\left[\mathrm{AOS}_{1} \mathrm{OH}\right] \mathrm{H}^{+}$ion and not from one isolated part. The similarities of the CAD results for $m / z 651$ and $m / z 781$ would be consistent with a remote site mechanism in which the site of protonation is either the aglycone or is mobile and does not directly induce the fragmentations observed.
Collisionally activated dissociation of $m / z$ 633. Another fragment ion of interest is observed at $m / z 633$ and could have several origins. First, this ion could be a primary fragment following protonation produced by cleavage of the $\mathrm{z}$ glycosidic $\mathrm{C}-\mathrm{O}$ bond on the terminal sugar to produce what Domon and Costello [9] refer to as the $Z_{2}$ ion. This ion at $m / z 633$ could also be a secondary fragment, as suggested by the abundance ratio of $m / z 651$ to $m / z 633$ in the FAB mass spectrum and in the CAD daughter ion spectra of $m / z$ 651. If $\mathrm{m} / z 633$ is produced by a loss of $\mathrm{H}_{2} \mathrm{O}$ from $\mathrm{m} / \mathrm{z}$ 651 , the $\mathrm{H}_{2} \mathrm{O}$ could be from either of the two sugars retained in the ion, or from the aglycone. If the ion at $m / z 651,\left[\mathrm{AOS}_{1} \mathrm{OS}_{2} \mathrm{OH}\right] \mathrm{H}^{+}$, loses a water molecule from the terminal $S_{2}$ sugar, then a daughter ion corresponding to the neutral loss of 130 , due to loss of an intact sugar molecule, should not be observed in the $B / E$ mass spectrum of $m / z$ 633. Instead, a daughter ion corresponding to the neutral loss of 112 should be observed, as discussed in Figure 6. Both of these neutral losses are observed yielding daughter ions at $\mathrm{m} / \mathrm{z}$ 503 and $m / z$ 521. Therefore, at least some of the water loss is from the terminal sugar, as evidenced by the large abundance at $m / z 521$ (which requires an intact aglycone and internal sugar). It is also possible that some of the $\left[\mathrm{AOS}_{1}-\mathrm{H}_{2} \mathrm{O} \mathrm{OS}_{2} \mathrm{OH}\right] \mathrm{H}^{+}$species is present as this would fragment upon $\mathrm{CAD}$ to produce daughter ions at $m / z 243$ (from the two sugars), $m / z 391$ (from the intact aglycone), and $m / z 503$ (from the loss of the terminal $S_{2}$ sugar), all of which are observed in the CAD spectrum of $m / z 633$. The third possible identity of $m / z 633$ is $\left[\mathrm{A}^{-\mathrm{H}_{2} O} \mathrm{OS}_{1} \mathrm{OS}_{2} \mathrm{OH}\right] \mathrm{H}^{+}$. This species should (and does) fragment upon CAD to produce $m / z$ 373 (from the dehydrated aglycone) and $m / z 503$ (from the $y$ glycosidic cleavage). This species could also form $m / z 243$ in the same manner that $m / z 781$ does, as the two sugars from this species resemble the sugar portion of the ion at $m / z 781$. Therefore, $\mathrm{H}_{2} \mathrm{O}$ losses are not specific as they do not come from any one substructural group. There are no daughter ions, present or absent, that can be used to make definitive structural assignments for the species at $m / z 633$.

Collisionally activated dissociation of $m / z 521$. The fragment ion observed at $m / z 521$ is also a prominent daughter ion of protonated digoxin and is identified as being structurally equivalent to a protonated cardiac glycoside containing only one sugar (see Table 1). The daughter ion mass spectrum of $m / z 521$ shows that substantial further fragmentation occurs. Again, the $\mathrm{CAD}$ results are consistent with a remote-site mechanism and/or a mobile proton. The parent ion at $\mathrm{m} / \mathrm{z}$ 521 does not yield a daughter ion at $m / z 243$, which is present in the CAD spectra of the ions at $m / z 781$, $m / z 651$, and $m / z$ 633. This ion at $m / z 243$ is indicative of the presence of two sugars, as noted in Table 1 , and therefore is not expected as a daughter ion of $m / z$ 521, which contains only one sugar. This is consistent with, 
and further supports, the assignments suggested by the peak matching results. The CAD of $m / z 521$ shows cleavage of the $A O-S_{1}$ bond to produce the daughter ion at $m / z 391$, which is also observed in the FAB mass spectrum, and is given the assignment $[\mathrm{AOH}] \mathrm{H}^{+}$ based on peak matching results. Also observed are the subsequent eliminations of three $\mathrm{H}_{2} \mathrm{O}$ molecules from the speries at $\mathrm{m} / \mathrm{z}$ 391. These water losses must be coming from the two - $\mathrm{OH}$ groups on the aglycone and the - $\mathrm{OH}$ group formed upon fragmentation (from the glycosidic oxygen with the $H$-shift). Though the relative abundances are slightly different, this same series of ions, $m / z 391,373,355$, and 337 , is present in the CAD spectra of $m / z 781,655$, and 633. These 300-400 dalton-series fragment ions will be discussed in more detail shortly.

Collisionally activated dissociation of $m / z 503$. The fragment ion at $\mathrm{m} / \mathrm{z} 503$ is structurally similar to the ion at $m / z 633$ in that these are both secondary fragments formed by a glycosidic bond cleavage and a water loss. The relative abundance ratio of $\mathrm{m} / \mathrm{z} 521 / 503$ is similar to that for the $m / z 651 / 633$ pair. This ion fragments upon CAD to give daughter ions at $m / z 391, m / z 373$, $m / z 355$, and $m / z 337$. The $m / z 503$ ion also loses one and two waters to form daughter ions at $m / z 485$ and $m / z 467$. The fragment ions at $m / z 391$ and $m / z 373$ are from neutral losses of 112 and 130 , as was observed for the CAD of $m / z$ 633. Once again the ion current at $m / z 503$ is probably a mixture of species with water loss from the aglycone portion of $m / z 521$ (which would show a neutral loss of 130 upon $(A D)$, water loss from the sugar (which would show a neutral loss of 112), and possibly some primary fragment from $m / z$ 781 (cleavage at the $\mathrm{z}$ glycosidic bond). The abundant daughter ion at $m / z 391$, which corresponds to a neutral loss of 112, suggests that a large percentage of $m / z$ 503 contains a sugar that is monodehydrated and that this species readity tragments at the glycosidic bond to produce the protonated aglycone species $[\mathrm{AOH}] \mathrm{H}^{+}$at $m / z 391$.

Collisionally activated dissociation of $m / z$ 391, $\mathrm{m} / \mathrm{z} 373, \mathrm{~m} / \mathrm{z}$ 355 , and $\mathrm{m} / \mathrm{z}$ 337. There are four ions in the 300-400 $u$ range that have two structural assignments for each nominal mass, as shown in Table 1. Peak matching with a resolution of $1 / 7000$ or better is used to distinguish between the two peaks with the same nominal mass but of different origin. The ion current observed at $m / z 391$ has two possible origins, the aglycone end and the saccharide end of digoxin. Both of these species are capable of losing up to three $\mathrm{H}_{2} \mathrm{O}$ molecules upon CAD. Thus the other three ions observed in this mass range, at $m / z 373, m / z 355$, and $m / z$ 337, can be, and are, formed by $\mathrm{H}_{2} \mathrm{O}$ losses from both species contributing to the ion current at $m / 2391$. The peak matching and high resolution scanning re- sults show that the largest contributor to the ion current for each of these four $m / z$ values is from the aglycone portion of the molecule. This follows with the previous observation that the majority of the types of fragment ions observed do contain the aglycone. The ion at $m / z 373$ has the strongest contribution from the sugar but this contribution still accounts for less than half of the total ion current at $m / z 373$ (see relative contributions in parentheses in Table 1). Unlike the other 300 series ions, the CAD analysis of $m / z 373$ does show some fragments indicative of the sugars. The daughter ions from sugars are observed at $m / z 243$, which represents a species containing two sugars, and at $m / 2$ 131 and $m / z 113$, which are derived from one sugar of the molecule, as identified in Table 1 . The CAD results for the other three ions at $m / z 391, m / z 355$, and $m / z$ 337 support the conclusion that they primarily contain the aglycone, since only $\mathrm{H}_{2} \mathrm{O}$ losses upon $\mathrm{CAD}$ are observed (no fragmentation of the steroid ring structure is observed). The relative abundances of the ions representative of these water losses increase as the parent ion becomes more unsaturated. For example, the loss of $\mathrm{H}_{2} \mathrm{O}$ from $m / z 391$ to form $m / z 373$ is not as prominent as the loss of $\mathrm{H}_{2} \mathrm{O}$ from the parent at $\mathrm{m} / \mathrm{z} 373$ upon CAD to form $m / z$ 355. This is supported by the data presented in Table 2 . This suggests that once one OH group is lost in the form of $\mathrm{H}_{2} \mathrm{O}$, subsequent dehydrations are more facile. It is expected, as observed, that dehydration of the aglycone would occur before demethylation or dehydrogenation. Consideration of the decomposition of substituted cyclohexanes can be used as a model to understand the energetics of $\mathrm{H}_{2} \mathrm{O}$ elimination versus $\mathrm{CH}_{4}$ elimination versus loss of $\mathrm{H}_{2}$ from the aglycone structure. The dehydration of cyclohexanol to form cyclohexene requires $+10.4 \mathrm{kcal} / \mathrm{mole}$ [28]. (Thermochemical estimates are based on data contained in ref 28 .) In contrast, $+18.1 \mathrm{kcal} / \mathrm{mole}$ is required to eliminate methane from methylcyclohexanol, and $+28.4 \mathrm{kcal} /$ mole is required to induce the dehydrogenalion of cyclohexane. Therefore, energetic considerations suggest that water losses are expected before loss of $\mathrm{CH}_{4}$ or $\mathrm{H}_{2}$ from a cyclic system such as the aglycone of digoxin.

The tecognition that the second $\mathrm{H}_{2} \mathrm{O}$ loss occurs more readily than the first is also observed for other ions, such as the pairs $m / z 651 / 633$ and $m / z 521 / 503$. The monodehydrated species in each pair (lower mass) loses another $\mathrm{H}_{2} \mathrm{O}$ more readily (upon $\mathrm{CAD}$ ) than the nondehydrated species, as seen in Table 2 . It is possible that, once a double bond is formed (upon $\mathrm{H}_{2} \mathrm{O}$ loss), the second loss is more facile.

Collisionally activated dissociation of $m / z 243$. The ion at $m / z 243$ is a prominent fragment ion in both the FAB mass spectrum of digoxin and the linked scan mass spectrum of protonated digoxin. This ion is unique in that it is isolated from any other peaks and is not associated with other ions $18 \mathrm{u}$ higher or lower in mass. 
Most other major fragment ions observed in the FAB mass spectrum have an ion $18 \mathrm{u}$ below them due to $\mathrm{H}_{2} \mathrm{O}$ loss. This ion at $m / z 243$ is observed as a daughter ion from $m / z 781, m / z 651, m / z 633, m / z$ 391, and $m / z$ 373. These are the only species that should be able to produce the fragment ion at $m / z 243$ by CAD if the assignment for this ion is correct as given in Table 1 . The species at $m / z 355$ and $m / z 337$ have already lost too many $\mathrm{H}_{2} \mathrm{Os}$ to form the ion at $m / z 243$. The assignment proposed in Table 1 for this ion at $\mathrm{m} / z 243$ is the same, minus one sugar, as that given to the ion at $m / z 373$ for the sugar portion of that doublet. These two ions may be formed by the same fragmentation mechanism that may differ from the mechanism that forms the ions containing the aglycone. The fact that the ion at $m / z 243$ does not lose $\mathrm{H}_{2} \mathrm{O}$ suggests that the sugars do not as readily lose $\mathrm{H}_{2} \mathrm{O}$ as does the aglycone. Further support for the proposed assignment of $m / z$ 243 is from the linked scan mass spectrum of this ion. The appearance of a daughter ion at $m / z 149$ proves that $m / z 243$ contains an intact terminal sugar. The ion at $m / z 149$ is from the terminal sugar with retention of the glycosidic oxygen, $\left[\mathrm{HOS}_{3} \mathrm{OH}\right] \mathrm{H}^{+}$.

The most abundant daughter ion observed by the CAD of $m / z 243$ is $m / z$ 97. It is also observed in the $\mathrm{FAB}$ mass spectrum of digoxin. The chemical formula of this ion is determined to be $\mathrm{C}_{6} \mathrm{H}_{9} \mathrm{O}^{+}$by peak matching (Table 1). From Table 2, it can be seen that this daughter ion is present to a minor extent in many of the $B / E$ spectra collected, but is only a significant daughter ion of the parent ions at $\mathrm{m} / \mathrm{z} 373$ and $m / z 243$. These two species contain a partially dehydrated sugar that leads to the possibility that the structure of $m / z 97$ is a completely dehydrated digitoxose (sugar) unit in the protonated form, structure (XI). This ion is designated as $\left[\mathrm{S}-\mathrm{H}_{2} \mathrm{O}\right] \mathrm{H}^{+}$in Table 1. It is unclear whether this ion comes from the terminal sugar, in which case it would be labeled as $\left[\mathrm{HOS}_{3}{ }^{-\mathrm{H}}\right.$ $\left.\mathrm{H}_{2} \mathrm{O}_{2}\right] \mathrm{H}^{+}$, or from an internal sugar, $\left[{ }^{+} \mathrm{H}_{2}-\mathrm{H}\right.$ $\left.-\mathrm{H}_{2} \mathrm{O}\right] \mathrm{H}^{+}$or $\left[{ }^{+\mathrm{H}_{1}} \mathrm{~S}_{1}-\mathrm{H}_{-}-\mathrm{H}_{2} \mathrm{O}\right] \mathrm{H}^{+}$. However, structure (XI) is supported by the results of the CAD of $m / z 97$. This $\mathrm{B} / \mathrm{E}$ mass spectrum of $m / z 97$ contained fragment ions corresponding to the loss of $\mathrm{CH}_{4}$ and $\mathrm{CO}$, which would be expected from this proposed structure, consistent with the presence of a methyl group and the ring oxygen atom.

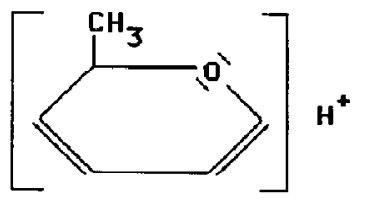

(XI)
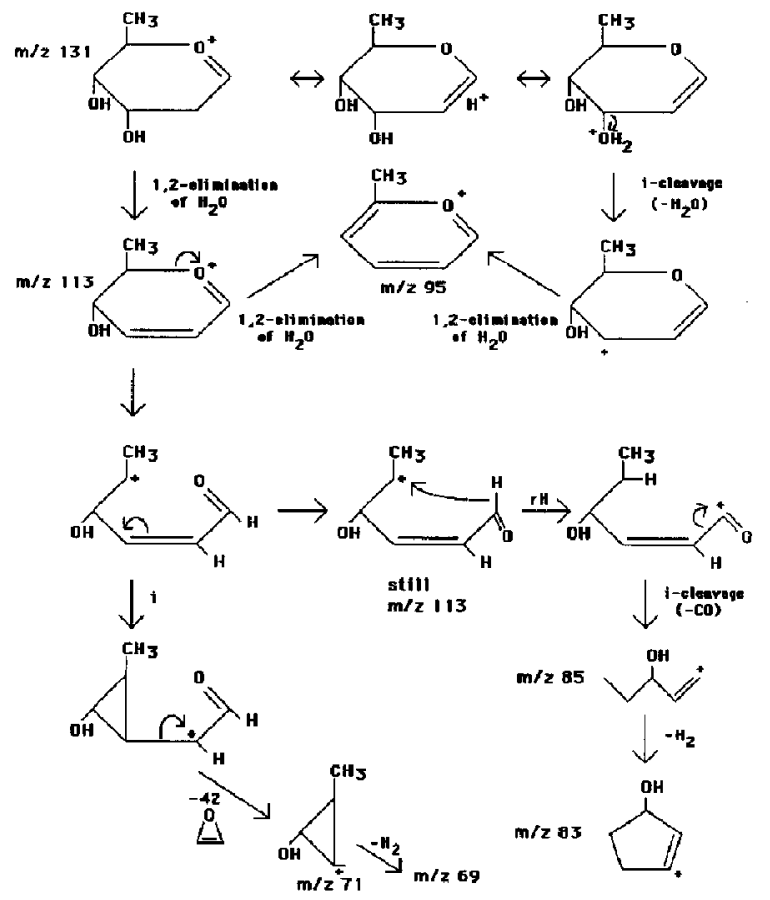

Figure 7. Possible mechanisms for the fragmentation of the parent ion at $m / z 131$ upon CAD to produce the ions observed in the linked scan (see Table 2).

Collisionally activated dissociation of $\mathrm{m} / \mathrm{z} 131$ and $\mathrm{m} / \mathrm{z} 113$. The two low mass fragment ions at $m / z 131$ and $m / z$ 113 are very abundant in the FAB mass spectrum of digoxin and appear to be terminal sugar fragments. This is supported by the results of peak matching data presented in Table 1 . The $m / z 131$ ion fragments upon $\mathrm{CAD}$ to give some interesting low mass ions. At the low collision gas pressure used for most of this study, the main fragment ion observed from $m / z 131$ is at $m / z 113$ due to loss of $\mathrm{H}_{2} \mathrm{O}$. If the collision gas pressure is increased, to attenuate $m / z 131$ by more than $10 \%$, more fragmentation results to give all the low mass fragments listed in Table 2 (between $m / z 69$ and $\mathrm{m} / \mathrm{z}$ 113). Possible mechanisms for the CAD of the primary ions at $m / z 131$ and $m / z 113$ to produce the low mass daughter ions observed in a $B / E$ linked scan are outlined in Figure 7. Inductive cleavages of rearrangement species and 1,2-eliminations are used to explain the fragmentation of $\mathrm{m} / \mathrm{z} 131$ and $\mathrm{m} / \mathrm{z} 113$. The daughter ion at $m / z 97$ is of low relative abundance compared to the other daughter ions from the CAD of $m / z 131$ and $m / z 113$. It is possible that this fragment is formed by the loss of $\mathrm{H}_{2} \mathrm{O}_{2}$ from the species at $m / z 131$ to give the structure proposed. However, due to the low relative abundance of this daughter ion and the uncertainty in the fragmentation pathway, $m / z 97$ is not included in the fragmentation scheme of $m / z 131$ and $m / z 113$ shown in Figure 7. 
Relevant results from the fast atom bombardment mass spectra of other cardiac glycosides. The effects of small structural changes in the analyte molecule on the FAB mass spectra and the B/E linked scan mass spectra of the $\left[\mathrm{M} \mid \mathrm{H}^{+}\right.$ions were investigated. Two cardiac glycosides, digitoxin and gitoxin, were chosen for study because of their differences in the aglycone portion of the molecule from digoxin. The structures of these two compounds are shown in Figure 1 where digitoxin is structure $E$ and gitoxin is structure $G$. Digitoxin has one less $\mathrm{OH}$ group on the aglycone than digoxin, and gitoxin has the same molecular formula but with different positioning of one of the OH groups on the aglycone ring structure (C-12 on digoxin and C-16 on gitoxin). Another compound, acetyldigitoxin (structure F) was chosen for its modification to the sugar portion of the compound. The aglycone of acetyldigitoxin is identical to that of digitoxin, but the terminal sugar contains an acetyl group. The FAB mass spectra and the $\mathrm{B} / \mathrm{E}$ spectra of the $[\mathrm{M}] \mathrm{H}^{+}$ions of digitoxin, gitoxin, and acetyldigitoxin were obtained and compared with the corresponding spectra of digoxin in order to determine whether changes in the aglycone portion or the sugar portion of digoxin have more effect on the types and relative abundances of the fragment ions observed. The mass spectra of these related compounds all contained relatively the same protonated fragments (and parent ions) as observed for digoxin, with some of the $m / z$ values shifted due to the introduced modifications from digoxin. For example, with the compound digitoxin, the ions in the $\mathrm{m} / \mathrm{z} 337$ to $\mathrm{m} / \mathrm{z} 391$ range that were given two assignments for digoxin (from the aglycone end and from the sugar portion of the molecule for the same $m / z$ value) were split into two series, separated by $16 \mathrm{u}$, due to the change in the mass of the aglycone portion of digitoxin. This further supports the double assignuments given to these fragment ions of digoxin in Table 1 . The relative abundances of the daughter ions in the $B / E$ linked scan mass spectra of the $[\mathrm{M}] \mathrm{H}^{+}$ions of the two compounds with aglycone modifications (digitoxin and gitoxin) are different from digoxin. The most notable changes are that the $\left[\mathrm{M}-\mathrm{H}_{2} \mathrm{O}\right] \mathrm{H}^{+}$ions are more abundant in the $\mathrm{B} / \mathrm{E}$ mass spectra of these two modified aglycone compounds than for digoxin. This observation is probably a result of the differences in locations, and hence reactivity, of the $-\mathrm{OH}$ groups on the aglycone portions of these compounds. The modifications to the sugar portion of the compound digitoxin do not produce any noticeable differences in the $\mathrm{FAB}$ mass spectrum or the $\mathrm{B} / \mathrm{E}$ spectrum of the $[\mathrm{M}] \mathrm{H}^{+}$ion of acetyldigitoxin from the corresponding spectra of digoxin with respect to the protonated species observed and their relative abundances. One exception is the shift in mass of the ions containing the terminal sugar with the added acetyl group. Therefore, small changes in the aglycone portion of these cardiac glycosides result in more dramatic mass spectral changes than do modifications to the sugar portion of the molecules. The differences in the $F A B$ and $B / E$ linked scan mass spectra produced by slight alterations in the aglycone suggest that the aglycone does play a major role in controlling the fragmentation mechanism(s) and may possibly be the site of charge localization. A possible explanation for the importance of this aglycone on the mechanisms of fragmentation could be related to energetics and the proton affinities of specific sites on the aglycone. However, there is no obvious site where the charge resides on the aglycone of digoxin. The modifications in the aglycone of these cardiac glycosides may affect the energy that the $[\mathrm{M}] \mathrm{H}^{+}$ion contains as it fragments via remote site processes and therefore may affect the relative abundances of the fragment ions observed.

\section{Conclusions}

The data presented from the FAB mass spectrum and the MS/MS analyses of all the major fragment ions of digoxin show that over half of the different types of fragment ions formed contain the aglycone portion of the molecule and that many different bonds are cleaved. The results we obtained from the FAB mass spectrum of digoxin can be closely compared with the reported $\mathrm{NH}_{3} \mathrm{CI}$ spectrum of digoxin [26]. All of the fragments, including those due to multiple $\mathrm{H}_{2} \mathrm{O}$ losses, that are observed in protonated form in the FAB mass spectrum are observed in the $\mathrm{NH}_{3} \mathrm{CI}$ spectrum as $\mathrm{NH}_{4}^{+}$adducts. This suggests that very similar fragmentation mechanisms are occurring with these two techniques and that the difference between protonation by glycerol and $\mathrm{NH}_{4}^{+}$adduct formation does not affect the fragmentation mechanism(s) significantly. If the fragment ions formed in the $\mathrm{NH}_{3} \mathrm{CI}$ experiment evolve from $[\mathrm{M}] \mathrm{NH}_{4}^{+}$, as they appear to, the charge resides on the ammonium ion and not on some part of the digoxin molecule itself. This rules out reaction 1 as a possible pathway of fragmentation because it requires that the charge reside on the oxygen of the glycosidic bond in order to induce fragmentation of this bond. Reactions 2 and 3 are possible fragmentation pathways for $\mathrm{NH}_{3} \mathrm{Cl}$, as well as protonation by glycerol fragment ions because the charge site is not required to be on the oxygen atom, as in reaction 1. However, further fragmentation of the primary fragments would be unlikely following reaction 2 because charge migration through the molecule is required for the formation of the secondary fragmentations observed. If the charge site in the adduct ion formed in $\mathrm{NH}_{3} \mathrm{CI}$ is localized on the $\mathrm{NH}_{4}^{+}$ion, then charge migration throughout the molecule would not be possible. Therefore, reaction 3 would not predict the production of the same fragment ions in the decomposition of protonated molecules and $\mathrm{NH}_{4}^{+}$ adducts. A remote site mechanism, reaction 4, provides the best explanation for the similarities in the fragmentations of digoxin observed with $\mathrm{FAB} / \mathrm{MS}$ and 
$\mathrm{NH}_{3} \mathrm{CI}$. In this case the charge site can be localized on the aglycone and induce fragmentation at remote sites throughout the molecule. As the charge is not directly involved in the fragmentation and no charge migration is required, it is expected, by reaction 4 , that the protonated ion and $\mathrm{NH}_{4}^{+}$adduct ion would produce the same fragmentation products, as observed, as long as the charge can be localized on the aglycone in both cases.

The data presented here from the mass spectrometry and MS/MS analysis of digoxin lend further support to the role of the remote site mechanism in the formation of the fragment ions observed. Reaction 1 can explain only a limited number of the types of fragmentations of digoxin observed. For instance, the ion at $m / z 131$ can be easily explained via reaction 1 by protonation of the oxygen atom of the terminal glycosidic bond, inducing fragmentation to produce the species at $m / z 131$. By this same mechanism, other fragment ions at $m / z 261$ and $m / z 391$ should be formed from protonation and fragmentation of the other two glycosidic bonds. However, the ion current at $m / z 391$ is primarily from the aglycone portion of the molecule (see Tables 1 and 2) and no ion is observed at $\mathrm{m} / \mathrm{z} 261$, in contradiction to what would be expected by reaction 1 . Therefore, reaction 1 fails to provide a consistent explanation of the fragmentation pathways for the decomposition of digoxin and is only a possible mechanism for the formation of a few fragment ions observed.

Reactions 2 and 3, based on charge-induced fragmentation, can explain the majority of the primary fragments observed in the FAB analysis of digoxin. It is possible that these mechanisms can provide pathways for the extensive fragmentation of the primary fragments as reported in Table 2 . The charge site must be able to migrate throughout the molecule following primary fragmentation in order to explain all of the ions observed in the MS/MS spectra, which may be possible with the protonated species. Based on reaction 3, competition for the charge should be determined by the relative basicity of the two competing sites. This holds true for the formation of $m / z 651$ and $m / z 521$ where fragmentation about the glycosidic bond, following reaction 3 , results in the charge site residing on the nonreducing end of the sugar that contains the aglycone portion of the molecule. This nonreducing end of the sugar contains a more basic site, due to the close proximity of two $-\mathrm{OH}$ groups, than does the reducing end of the terminal sugar, which has only a ring oxygen and double bond in close proximity. However, this mechanism does not hold true for the formation of the fragment ion at $\mathrm{m} / \mathrm{z}$ 391. This species is primarily composed of the aglycone portion of the molecule, even though the aglycone has no $-\mathrm{OH}$ group or other functional group near the site of protonation/fragmentation to increase the basicity, whereas the sugar moiety has a ring oxygen and double bond near the competing site. In this case the aglycone end is not more basic than the sugar end and therefore should not effectively compete for the $\mathrm{H}^{+}$. Therefore, some other fragmentation mechanism is required to explain the production of $m / z 391$.

The remote site fragmentation mechanism can explain a high proportion of the fragment ions containing the aglycone and the occurrence of the majority of the ions observed if the charge site is localized on the aglycone. This requires that a basic site or stable cation be formed for the charge to remain localized on the aglycone throughout the extensive fragmentation obscrved. There is no obvious basic site in the digoxin molecule on the aglycone that has a higher proton affinity than parts of the sugars, as can be seen in Figure 5. However, the five-membered ring of the aglycone provides a very plausible site for charge localization. Protonation of the oxygen atom in this strained five-membered ring could induce ring cleavage followed by $\mathbf{H}$ migration to produce a tertiary cation. This is shown in reaction 5 . The formation of the tertiary cation provides a charge site that hinders free migration of the charge back onto the sugars. This is one possible way that charge localization can occur on the aglycone to allow for remote site fragmentation to produce the majority of the ions observed. The modifications in the aglycone that were investigated with digitoxin and gitoxin would not prevent this charge localization and therefore would still allow for the remote site fragmentation mechanism to occur.
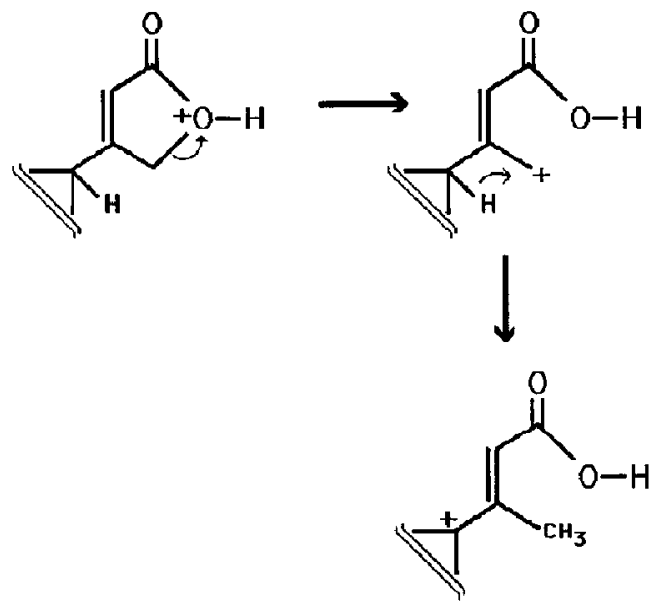

Thermodynamic considerations of these fragmentation processes support remote site fragmentation mechanisms. Consider the case of the $[\mathrm{M}] \mathrm{H}^{+}$ion of a multifunctional compound containing at least two $-\mathrm{OH}$ groups, where one is protonated. If the ion is formed with excess energy, fragmentation can occur. In such a situation, ionic pathways are not necessarily 
more energetically favored than neutral (remote site) processes. These pathways are shown in reaction 6 . For example, pathway $B$, elimination of water due to an inductive cleavage, yielding a carbocation, requires approximately $23 \mathrm{kcal} / \mathrm{mol}$ [28]. In contrast, pathway $A$, a remote site fragmentation to form a double bond and $\mathrm{H}_{2} \mathrm{O}$, only requires $12 \mathrm{kcal} / \mathrm{mol}$ [28]. Thus, there is no thermodynamic basis for excluding remote site eliminations because they should be competitive with ionic fragmentation mechanisms.

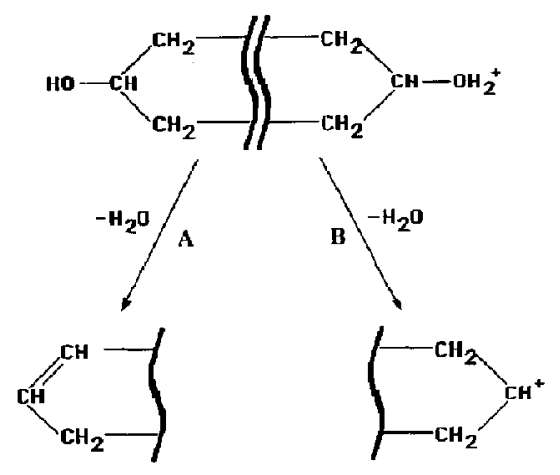

This remote site mechanism, however, does not explain the large ion currents at $m / z 131$ and $m / z 113$ that are present in the $\mathrm{FAB}$ analysis of digoxin. It is possible that reaction 1 or 3 is the primary pathway for producing these two ions. According to Figure 5 the site with the highest proton affinity is on the terminal sugar. This could allow for charge-induced fragmentation via reaction 1 or 3 to produce these two abundant low mass fragment ions at $m / z 113$ and $m / z 131$.

It is highly probable that more than one mechanism is involved in forming all of the fragment ions observed in this FAB mass spectrometric study of digoxin. A combination of these mechanisms can explain the results obtained satisfactorily. More exten sive studies on similar compounds need to be performed to determine the exact fragmentation pathways involved in the formation of each fragment iun observed by both primary and secondary fragmentation.

We have attempted to take a fundamental approach to the interpretation of the mass spectra obtained in the $F A B$ and $C A D$ experiments of digoxin and other related cardiac glycosides. The extensive fragmentation observed for these compounds is certainly not uncommon in FAB analyses of such highly functionalized compounds. It is possible that the extensive fragmentation observed for these types of complex compounds may occur for different reasons and that fragmentation patterns may not be transferable to different types of compounds. However, the information presented here may provide a starting point for similar detailed analyses of the mechanisms of fragmentation of protonated molecules from other highly functionalized compounds by FAB.

\section{Acknowledgments}

This work was supported by a grant from the Biotechnology Research Program of the Division of Research Resources of NIH (RR-00480-20). We thank Gary A. Schultz for early discussions and CAD experiments that led to the development of this project, and John T. Stults for conversations concerning the B/E linked scanning technique.

\section{References}

1. McLafferty, F. W. Interpretation of Mass Spectra, 3rd ed.; University Science: Mill Valley, CA, 1981.

2. Kassel, D. B.; Glerum, M.; Robinson, B. H.; Sweeley, C. C. Anal. Biochem. 1989, 176, 382.

3. Sunner, J. A.; Kulatunga, R.; Kebarle, P.; Anal. Chem. 1986, 58,1312 .

4. Holmes, J. L.; Org. Mass Spectrom. 1985, 20, 169.

5. Crow, F. W.; Tomer, K. B.; Looker, J. H.; Gross, M. L. Anal. Biocheth. 1986, 155, 286.

6. Instruction Manual for MS-LN09/08/11, Linked Neutral Loss Scan Program, JEOL, Ltd., Tokyo, Japan, No. IMS-LNS, p. 10. Sato, K.; Asada, T.; Ishihara, M.; Kunihiro, F.; Kammei, Y.; Kubota, E.; Costello, C. E.; Martin, S. A.; Scoble, H. A.; Biemann, K. Anal. Chem. 1987, 59, 1652.

7. Holmes, J. L.; Szulejko, J. E. Org. Mass Spectrom. 1983, 18, 273.

8. Light, K. J.; Kassel, D. B.; Allison, J.; Biomed. Environ. Mass Spectrom. 1989, 18, 177

9. Domon, B.; Costello, C. E. Glycoconjugate J. 1988, 5, 397.

10. Bochkov, A, F; Zaikov, G. E. Chemistry of the O-Glycosidic Bond: Fonnation and Cleavage; Pergamon: Oxford, 1979; pp $179-181$.

11. Busch, K. L.; Glish, G. L.; McLuckey, S. A. Mass Spectrometry / Mass Spectrometry: Techniques and Applications of Tandem Mass Spectrometry; VCH: New York, 1988.

12. (a) Field, F. H. In MTP International Review of Science Mass Spectrometry Series One; Maccoll, A., Ed.; Butterworths, 1972. (b) McLafferty, F. W. Org. Mass Spcctrom. 1980, 15, 114.

13. (a) Ichikawa, H.; Harrison, A. G. Org. Mass Spectrom. 1978, 13, 389. (b) Martinsen, D. P.; Buttrill, S. E., Jr. Org. Mass Spectrom. 1976, 11, 762. (c) Pesheck, C. V., Buttrill, S. E., Ir. 1. Amer. Chem. Soc. 1974, 96, 6027. (d) Pollack, S. K.; Devlin, J. L. III; Summerhays, K. D.; Taft, R. W.; Hehre, W. J. J. Amer. Chem. Soc. 1977, 99, 4583.

14. Go, K.; Kartha, G.; Chen, J. P. Acta Cryst, 1980, B36, 1811.

15. Lias, S. G.; Liebman, J. F., Levin, R. D. I. Phys. Chem. Ref. Data 1984, 13, 695.

16. (a) Aue, D. HI; Webb, II. M.; Bowers, M. T.; J. Amer. Chem. Soc. 1973, 95, 2699. (b) Yamdagni, R.; Kebarle, P. J. Amer. Chem. Soc. 1973, 95, 3504. (c) Longevialle, P.; Milne, G. W. A.; Fales, H. M. I. Amer. Chem. Soc. 1973, 95, 6666. (d) Houriet, R.; Rufenacht, H.; Carrupt, P. A.; Vogel, P.; Tichy, M. J. Amer. Chem. Soc. 1983, 105, 3417. (e) Davis, D. V.; Cooks, R. G. Org. Mass Spectrom. 1981, 16, 176. (f) Houriet, R.; Rufenacht, H.; Stahl, D.; Tichy, M.; Longevialle, P. Org. Mass Spectrom. 1985, 20, 300. (g) Nacson, S.; Harrison, A. G.; Davidson, W. R. Org. Mass Spectrom. 1986, 21, 317. (h) Longevialle, P.; Girard, J.-P.; Rossi, J.-C.; Tichy, M. Org, Mass Spectrom. 1979, 14, 414. (i) McMahon, A. W.; Chadikun, F.; Harrison, A. G.; March, R. E. Int. I. Mass Spectrom. Ion Process. 1989, 87, 275.

17. Winkler, J.; McLafferty, F. W. Tetrahedron 1974, 30, 2971. 
18. Michnowicz, J.; Munson, B. Org. Mass Spectrom. 1972, 6, 283.

19. Neumann, G. M.; Derrick, P. J. Aust. J. Chem. 1984, 37, 2261.

20. (a) Tsang, C. W.; Harrison, A. G. J. Amer. Chem. Soc. 1976, 98, 1301. (b) Mandelbaum, A.; Bicmann, K. J. Amer. Chem. Soc. 1968, 90, 2975.

21. (a) Johnnson, R. S.; Martin, S. A.; Biemann, K. Int. J. Mass Spectrom. Ion Process. 1988, 86, 137. (b) Kiryushkin, A. A.; Fales, H. M.; Axenrod, T.; Gilbert, E. J.; Milne, G. W. A. Org. Mass Spectrom. 1971, 5, 19. (c) Winnik, M. A. Org. Mass Spectrom. 1974, 9, 920.

22. Bowen, R. D.; Stapelton, B. J.; Williams, D. H. J. Chem. Soc. Chem. Contmin. 1978, 24.

23. Jensen, N. J.; Tomer, K. B.; Gross, M. L. J. Amer, Chem. Soc. 1985, 107, 1863.

24. Adams, J. Mass Spectrom. Rev. 1990, 9, 141.

25. Wysocki, V. H.; Bier, M. E.; Cooks, R. G. Org. Mass Spectrom. 1988, 23, 627.

26. Vine, J.; Brown, L.; Boutagy, J.; Thomas, R.; Nelson, D. Biomed. Mass Spectrom. 1979, 6, 415.

27. Adams, J.; Gross, M. L. 1. Amer. Chem. Soc. 1989, 111, 435.

28. Lias, S. G.; Bartmess, J. E.; Liebman, J. F.; Holmes, J. L.; Levin, R. D.; Mallard, W. G. J. Phys. Chem. Ref. Data 1988, 17, Suppl. 1.

\section{Appendix}

The proton affinities listed in Figure 5 for the various sites in digoxin, as indicated in Figure 4, are estimated as follows. Three types of protonation sites are present. First, we consider simple functional groups such as double bonds (site a), $-\mathrm{OH}$ groups (site $b$ ), ketooxygens (site $d$ ), ring (ether) oxygens (site $f$ ), and glycosidic (ether) oxygens (site $i$ ). In these cases, small, simple molecules containing such functional groups are used as models. Thus, the proton affinities of these sites are based on the PA of the following molecules: site $a$ : 2-butene; site $b$ : isopropanol; site $d$ : acetone; site $f$ : tetrahydropyran; and site $i$ : isopropyl ether. The second type of protonation site is represented by compounds containing more complex functional groups or multiple functional groups. For example, site $e$ is represented by an ester, which has a PA different from that of an ether or a ketone. The PA of sile $e$ is estimated based on the PA of methyl acetate. In a similar way, site $c$ is considered to be similar to that found in the propenal molecule.
The third type of protonation site involves multiple interactions from heteroatoms/functional groups that are in close proximity. Many studies reported an increase in the stability of the protonated species with the addition of functional groups, such as $-\mathrm{OH}$, to the molecule [16]. This is believed to be due to intramolecular $\mathrm{H}$-bonding with these functional groups upon protonation. For example, butanol has a PA of $191 \mathrm{kcal} / \mathrm{mol}$ [15] compared to 1,2,4-butanetriol, which has a PA of $216 \mathrm{kcal} / \mathrm{mol}$ [3]. This increase in PA of $25 \mathrm{kcal} / \mathrm{mol}$ can be attributed to the two extra $-\mathrm{OH}$ groups, which allow for multiple $\mathrm{H}$-bonding interactions that increase the stability of the protonated species. Following this pattern, the PA of propanol, $190 \mathrm{kcal} / \mathrm{mol}$ [15] can be compared to the PA of glycerol, which is $209 \mathrm{kcal} / \mathrm{mol}$ [3]. In this case, the addition of two - $\mathrm{OH}$ groups leads to an increase in the PA of the molecule of approximately $19 \mathrm{kcal} / \mathrm{mol}$. Therefore, we propose that similar $\mathrm{H}$-bonding interactions with a corresponding increase in PA occur with the molecule digoxin when functional groups such as $-\mathrm{OH}$ groups, ring oxygens, and glycoside oxygens are in close proximity to each other, due to the stereochemistry of the molecule. We have conservatively proposed, based on the above PA values for linear mono and triols, that the interaction of a single - $\mathrm{OH}$ group with an $-\mathrm{OR}$ group (such as the glycosidic oxygen site on digoxin) results in an increase in PA of the more basic site of approximately $5 \mathrm{kcal} / \mathrm{mol}$. For instance, site $l$ has two $-\mathrm{OH}$ groups near the - OR (glycosidic $\mathrm{O}$ ), all of which are on the same side of the ring and have the potential for $\mathrm{H}$-bonding. If the presence of each $-\mathrm{OH}$ group increases the PA of this site by at least $5 \mathrm{kcal} / \mathrm{mol}$, then site $l$ would have a PA of at least $10 \mathrm{kcal} / \mathrm{mol}$ above the PA of the glycosidic oxygen (site i) alone. This is represented in Figure 5 as a shaded region above the value for site $i_{r}$ due to the uncertainty of these estimates and interactions. In a similar way, it has been estimated that the presence of a ring oxygen near a glycosidic oxygen (site $j$ ) may increase the PA of that site by at least $3 \mathrm{kcal} / \mathrm{mol}$. These estimates for the proton affinities for the possible sites of protonation on digoxin, based on similar organic molecules and the possible multifunctional interactions that have been shown to occur for other molecules, are presented in Figure 5. 